\title{
MHC Class II Antigen Presentation by Dendritic Cells Regulated through Endosomal Sorting
}

\author{
Toine ten Broeke ${ }^{1}$, Richard Wubbolts, and Willem Stoorvogel \\ Utrecht University, Faculty of Veterinary Medicine, Department of Biochemistry and Cell Biology, \\ Yalelaan 2, 3584 CM, Utrecht, The Netherlands \\ Correspondence: w.stoorvogel@uu.nl
}

\begin{abstract}
For the initiation of adaptive immune responses, dendritic cells present antigenic peptides in association with major histocompatibility complex class II (MHCII) to naïve CD4 ${ }^{+} \mathrm{T}$ lymphocytes. In this review, we discuss how antigen presentation is regulated through intracellular processing and trafficking of MHCII. Newly synthesized MHCII is chaperoned by the invariant chain to endosomes, where peptides from endocytosed pathogens can bind. In nonactivated dendritic cells, peptide-loaded $\mathrm{MHCI}$ is ubiquitinated and consequently sorted by the ESCRT machinery to intraluminal vesicles of multivesicular bodies, ultimately leading to lysosomal degradation. Ubiquitination of newly synthesized $\mathrm{MHCll}$ is blocked when dendritic cells are activated, now allowing its transfer to the cell surface. This mode of regulation for $\mathrm{MHCll}$ is a prime example of how molecular processing and sorting at multivesicular bodies can determine the expression of signaling receptors at the plasma membrane.
\end{abstract}

$D_{\text {res }}$ endritic cells (DCs) are present throughout peripheral tissues, where they constitutively sample their environment for the presence of pathogens and diseased cells through uptake of soluble and particulate matter by endocytic mechanisms, including clathrin-mediated endocytosis, phagocytosis, macropinocytosis, and trogocytosis. Trogocytosis refers to uptake of membrane and associated molecules from one cell by another. After endocytic uptake, both environmental "self" proteins and proteins from pathogenic origin can be processed into peptides for loading onto major histocompatibility complex (MHC) molecules. Peptides can be generated either by lysosomal proteases in the endocytic pathway, or by proteasomes when endocytosed proteins are transferred across the endosomal membrane into the cytosol. Thus, generated peptides may associate intracellularly with either MHC class I (MHCI) or MHC class II (MHCII) molecules, and in that context can be transferred to and displayed at the plasma membrane. MHC-peptide complexes can be recognized by $\mathrm{T}$ cells upon migration of DCs to lymphoid tissues (Guermonprez et al. 2002). In the absence of danger signals, DCs remain in a "resting" or "immature" state and display endogenous "self" peptides to maintain peripheral tolerance (Steinman et al. 2003; Schmidt et al. 2012). However, DCs also survey their

${ }^{1}$ Present address: Laboratory for Translational Immunology, Immunotherapy Laboratory, University Medical Center, Utrecht 3584 EA, The Netherlands.

Editors: Sandra L. Schmid, Alexander Sorkin, and Marino Zerial

Additional Perspectives on Endocytosis available at www.cshperspectives.org

Copyright (C) 2013 Cold Spring Harbor Laboratory Press; all rights reserved; doi: 10.1101/cshperspect.a016873

Cite this article as Cold Spring Harb Perspect Biol 2013;5:a016873 
T. ten Broeke et al.

environment with a collection of innate patternrecognition receptors (PRRs), including Tolllike receptors (TLR), C-type lectins, and nucleotide oligomerization domain (NOD)-like receptors, which collectively recognize a wide array of conserved pathogen-associated molecular patterns (PAMPs) and damage-associated molecular patterns (DAMPs), with the latter representing (altered) "self" molecules that are released by dying cells or expressed by tumor cells. DCs that are activated through their PRRs or by inflammatory cytokines differentiate into phenotypes that can stimulate adaptive immune responses (Reis e Sousa 2006; Joffre et al. 2009). Characteristic features of DC differentiation or "maturation" include a transient increase in phagocytosis and macropinocytosis for efficient antigen uptake, increased surface expression of costimulatory molecules (e.g., CD86, CD80, CD40), and enhanced potential to migrate from peripheral tissues to the local lymphoid tissues for interaction with $\mathrm{T}$ cells (West et al. 2004; Reis e Sousa 2006). Several other stimuli, for example, TNF- $\alpha$, can drive alternative DC maturation programs that result in tolerogenic rather than immunogenic DCs (Menges et al. 2002; Tan and O'Neill 2005; Cools et al. 2007; Maldonado and von Andrian 2010).

MHC molecules direct antigen specificity for adaptive immunity toward invading pathogens and malignant cells. MHCI on DCs predominantly helps elimination of infected and malignant cells through activation of antigenspecific $\mathrm{CD} 8^{+}$cytotoxic T cells. MHCI-driven cell killing by cytotoxic $\mathrm{T}$ cells, however, also requires licensing by DCs through MHCII-dependent activation of $\mathrm{CD}^{+}$helper $\mathrm{T}$ cells. In addition, MHCII on DCs serves to mount humeral immune responses and to instruct regulatory $\mathrm{T}$ cells and memory $\mathrm{T}$ cells. In contrast to MHCII, MHCI is expressed by nearly all cell types, and in nonprofessional antigen-presenting cells is exclusively loaded with peptides that are generated from cytosolic proteins by the ubiquitin/proteasome system. Cytosolic peptides can be translocated into the lumen of the endoplasmic reticulum (ER) for loading onto MHCI with the help of a dedicated peptideloading complex (Cresswell et al. 2005). Pep- tide-loaded MHCI is then transported out of the ER via the Golgi apparatus to the plasma membrane, where it is stably exposed. Infected cells that display pathogen-derived peptides on MHCI can be killed by cytotoxic $\mathrm{T}$ cells that specifically recognize relevant $\mathrm{MHCI}$-peptide complexes. A unique feature of DCs is their ability to also present peptides from endocytosed material via MHCI, a process called "cross-presentation." Cross-presentation by DCs is essential for the activation of naïve $\mathrm{T}$ cells to drive MHCI-restricted immune responses against tumor cells and cells other than DCs that are infected by pathogens. The mechanisms by which peptides from exogenously acquired proteins are generated and delivered to MHCI molecules in DCs have been discussed elsewhere (Amigorena and Savina 2010; Segura and Villadangos 2011; Joffre et al. 2012) and are beyond the scope of this review.

Although MHCI is expressed by all cells, expression of MHCII is restricted mainly to "professional" antigen-presenting cells (APCs), including DCs, macrophages, and B cells (Guermonprez et al. 2002; Trombetta and Mellman 2005). However, constitutive MHCII expression by non-APCs in the absence of costimulatory molecules, for example, by epithelial cells, has an important role in maintaining peripheral tolerance (Krupnick et al. 2005; Kreisel et al. 2010). Yet other cell types can be induced to express MHCII by certain stimuli, for example, by the cytokine IFN- $\gamma$ (Pober et al. 1983; Geppert and Lipsky 1985; Romieu-Mourez et al. 2007; Mulder et al. 2011). On the transcriptional level, MHCII expression is controlled by a complex of DNA-binding proteins, also referred to as the MHCII enhanceosome, and activation of this complex requires association with the MHCII transactivator (CIITA) (Jabrane-Ferrat et al. 2003; Choi et al. 2011).

Peptides that bind to MHCII molecules are generated within the endocytic tract by limited proteolysis of endocytosed protein (complexes), or alternatively, of cytosolic material that entered the endocytic tract via autophagy (Dengjel et al. 2005; Crotzer and Blum 2010; Kondylis et al. 2013). In professional antigen-presenting cells, the organelles at which MHCII peptide 
loading occurs mainly constitute late endosomes, although lysosomes have also been implicated (Geuze 1998). Together, these endocytic compartments are also referred to as MHCII compartments (MIICs) (Peters et al. 1991; Kleijmeer et al. 1997, 2001). DCs constitutively synthesize MHCII, which, in the absence of pathogen, are all loaded with "self" peptides in MIICs. In the absence of danger signals, however, cellsurface exposure of peptide loaded MHCII ( $\mathrm{pMHCII}$ ) is generally kept low through rapid sorting to and degradation in lysosomes. Limited exposure of self-peptide-loaded MHCII, in the absence of costimulatory signals, provides cues that support immune tolerance. Contrary to immature DCs, activated DCs efficiently convert to stable expressors of newly formed pMHCII complexes at their plasma membrane to increase the chance of interaction with TCRs on $\mathrm{CD}^{+} \mathrm{T}$ cells. The distinctive mechanisms and pathways for MHCI and MHCII antigen loading and trafficking have recently been compared in several excellent reviews (Neefjes et al. 2011; Blum et al. 2013; Mantegazza et al. 2013). The present review focuses in depth on mechanisms and pathways that regulate and determine the expression of pMHCII complexes at the plasma membrane of DCs.

\section{BIOSYNTHESIS OF MHCII}

MHCII consists of a noncovalently associated complex of two type I transmembrane glycoproteins, designated $\alpha$ chain and $\beta$ chain (Fig. 1). The $\alpha$ chain of MHCII has a molecular weight of $33-35 \mathrm{kDa}$ and contains two sites for $\mathrm{N}$-linked glycosylation. The $\beta$ chain has a slightly lower molecular weight of $25-30 \mathrm{kDa}$ and contains one amino-linked glycosylation site. Both chains have a short carboxy-terminal cytoplasmic and a single transmembrane domain. Together, their exoplasmic domains form a groove that can accommodate a large variety of peptides of 13-25 amino acids in length. Longer unfolded protein stretches have also been shown to bind, but at low frequencies, and these are prone to be trimmed after binding to MHCII (Watts 2012). The variance in peptide binding is to ensure immune responses toward many distinct antigens. Peptides require, however, specific and correctly spaced anchor residues for stable binding to a particular haplotype of MHCII. Individuals express multiple types of the polymorphic MHCII complexes (in humans encoded by the HLA-DR, DP, and DQ loci, and in mice, I-A and I-E), each covering a spectrum of peptides. In addition, MHCII polymorphism within populations of organisms supplies distinct peptide-binding specificities that further increase the potential to fight invading pathogens.

MHCII-associated peptides are largely derived from proteins (complexes) that have been hydrolyzed in endosomal or lysosomal compartments (Amigorena et al. 1995; Castellino and Germain 1995; Lutz et al. 1997). Although MHCII $\alpha$ chains and $\beta$ chains already assemble and form peptide-binding sites in the ER, they capture peptides only after arriving at the endocytic pathway. Premature peptide loading is prevented by the invariant chain (Ii, also called CD74) (Teyton et al. 1990; Busch et al. 1996). Ii binds the MHCII peptide-binding groove with a region in its luminal domain that is called CLIP (for class-II-associated invariant chain peptide) (Rudensky et al. 1991; Chicz et al. 1992; Riberdy et al. 1992; Sette et al. 1992; Freisewinkel et al. 1993). Normally, Ii is synthesized in excess over MHCII, ensuring Ii rather than peptide binding to MHCII (Kvist et al. 1982; Sekaly et al. 1986; Marks et al. 1990; Pieters et al. 1991). Peptides that are transferred into the ER by TAP, for potential binding to $\mathrm{MHCI}$, indeed have poor potential to bind MHCII (Bikoff et al. 1993; Viville et al. 1993; Elliott et al. 1994; Romagnoli and Germain 1994; Busch et al. 1996). Ii is encoded outside the MHC gene region, but its expression, like MHCII, is under the control of CIITA (Reith et al. 2005). Ii is a monomorphic type II transmembrane protein, hence its name, but alternative initiation sites and splicing result in multiple forms that are named after their relative molecular weight. The shortest form of Ii, $\mathrm{p} 31$ in mice and p33 in man, is expressed most prominently. Because of alternative splicing, mice and humans also express p41 and p43, respectively (Strubin et al. 1986; Koch et al. 1987; O’Sullivan et al. 1987). The additional sequence in their exoplasmic domain has protease inhibitory ac- 
T. ten Broeke et al.

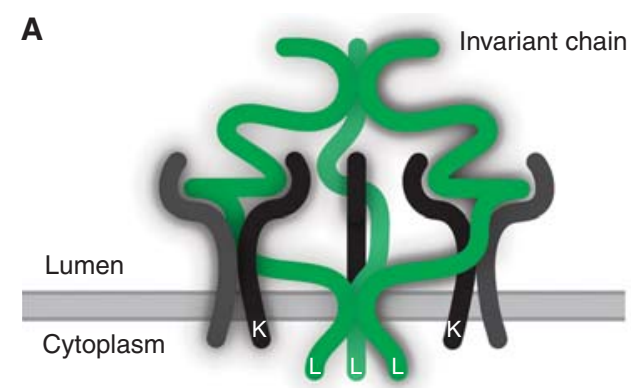

$(\alpha \beta l i)_{3}$

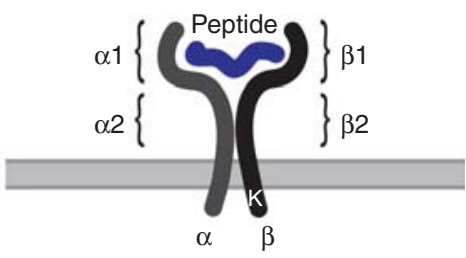

Peptide-loaded MHC class II complex
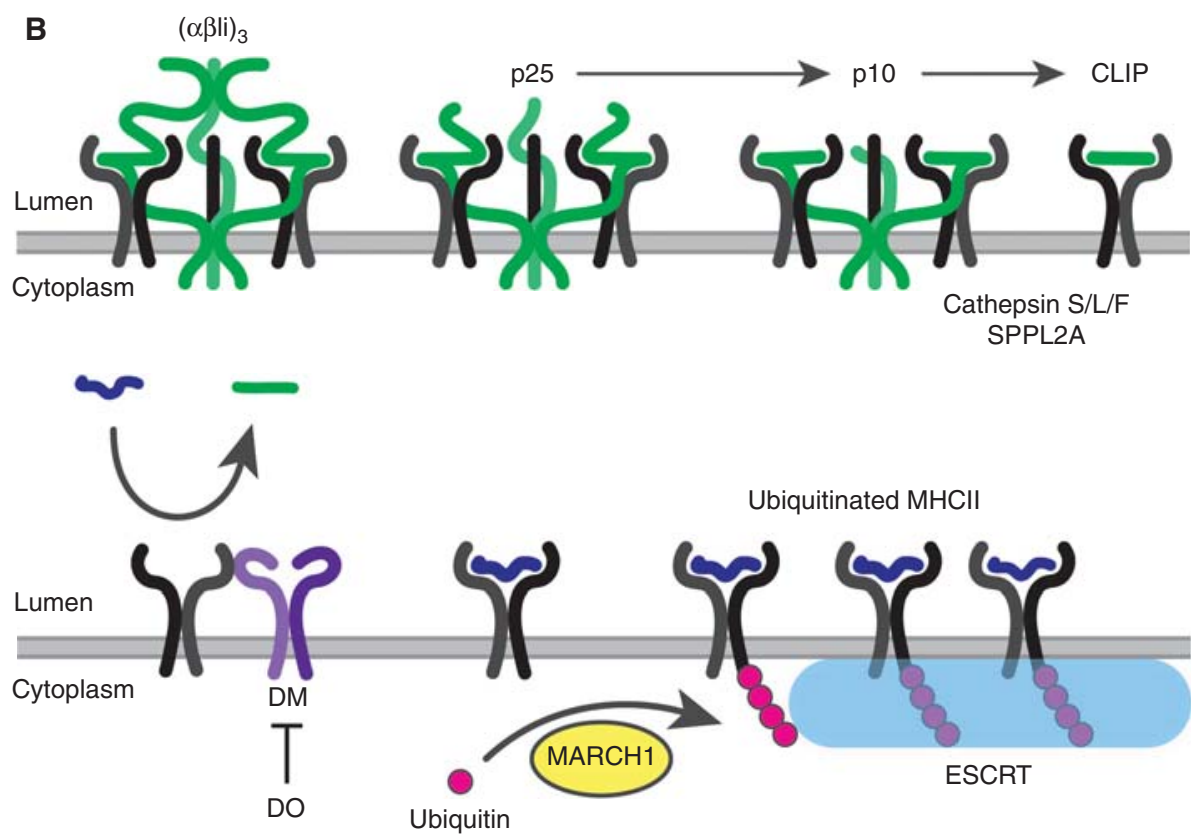

Figure 1. MHCII processing. ( $A$ ) On the left, a nonameric $(\alpha \beta \mathrm{Ii})_{3}$ MHCII complex with trimerized Ii (green), MHCII $\alpha$ (gray), and $\beta$ (black). Leucine-based sorting motifs in Ii (L) and the site for MHCII $\beta$ ubiquitination $(\mathrm{K})$ are indicated. (Gray bar) The membrane. On the right, pMHCII with bound peptide (blue) and the $\alpha 1, \alpha 2$, $\beta 1$, and $\beta 2$ domains of the $\alpha$ and $\beta$ chains. (B) Schematic representation of progressive Ii processing, MHCII peptide loading, and ubiquitination. The sites of action for cathepsin S/L/F, SPPL2A, DM, DO, MARCH1, and ESCRT are indicated, and their roles are explained in the text.

tivity especially to the cysteine protease cathep$\sin$ L (Koch et al. 1989; Bevec et al. 1996; Mihelič et al. 2008) and influences the antigen-processing capacity of endosomes (Peterson and Miller 1992). In humans, but not in mice, an alternative start codon provides two additional Ii isoforms, p35 and p45, carrying a cytoplasmic extension that is shielded only after correct folding of the MHCII-Ii complex and, when exposed, serves as an ER-retention motif. After synthesis in the ER, Ii forms trimers in which all forms of Ii can be incorporated, although the p31/33 form is most prominently present (Lamb and Cresswell 1992; Arunachalam et al. 1994). Trimerization of Ii is promoted by intermolecular associations of transmembrane and luminal domains (Bijlmakers et al. 1994; Gedde-Dahl et al. 1997; Ashman and Miller 1999). In the ER, three 
MHCII $\alpha \beta$ heterodimers associate with one Ii trimer, generating nonameric $(\alpha \beta \mathrm{Ii})_{3}$ complexes (MHCII-Ii) (Fig. 1A) (Lamb and Cresswell 1992). MHCII $\alpha \beta$ dimers are stabilized by association with Ii; absence of Ii results in accumulation of misfolded MHCII molecules in the ER (Anderson and Miller 1992; Schaiff et al. 1992; Marks et al 1995). Ii not only assists MHCII folding and covers the peptide-binding site of MHCII, but also chaperones MHCII via the Golgi and trans-Golgi network (TGN) to endosomes (Fig. 2). Both a direct route from the TGN to endosomes (Neefjes et al. 1990; Benaroch et al. 1995; Warmerdam et al. 1996; Liu et al. 1998) and an indirect transport pathway via the plasma membrane (Roche et al. 1993; Bremnes et al. 1994; Wang et al. 1997; Dugast et al. 2005; McCormick et al. 2005) are involved. Newly synthesized MHCII-Ii is directed to the endocytic system with the aid of two classical leucinebased sorting motifs (Bonifacino and Traub 2003) that are embedded within the Ii cytoplasmic domain (Pieters et al. 1993; Odorizzi et al. 1994; Rodionov and Bakke 1998; Hofmann et al. 1999). These motifs can interact with the cytosolic trans-Golgi-network-associated proteinsorting complex AP1 (Salamero et al. 1996) and with the plasma membrane adaptor AP2 (Rodionov and Bakke 1998; Hofmann et al. 1999). The cytoplasmic extension of the human p35 isoform can be phosphorylated by protein kinase $\mathrm{C}$, a requirement that may be essential for chaperoning MHCII directly from the TGN to endosomes (Spiro and Quaranta 1989; Anderson and Roche 1998; Anderson et al. 1999), and in human cells, the AP1-directed pathway may become important particularly during DC maturation (Santambrogio et al. 2005). MHCII-Ii complexes that are deposited on the plasma membrane are rapidly taken up by clathrin-mediated endocytosis, and this process is largely driven by recognition of the two leucine-based motifs encoded in the cytoplasmic domain of Ii by the clathrin adaptor AP2 (Dugast et al. 2005; McCormick et al. 2005). In any case, MHCII-Ii must pass transferrin receptor-positive early endosomes to reach subsequent endocytic compartments where antigen loading occurs (Benaroch et al. 1995; Pond and Watts 1999). In endosomes, MHCII is loaded with peptides only after Ii is degraded by proteolysis (Jones et al. 1979; Owen et al. 1981; Charron et al. 1983; Rudd et al. 1985; Roche and Cresswell 1990, 1991; Teyton et al. 1990). Ii is degraded by multiple proteases in defined sequential cleavage steps, starting at the carboxy-terminal luminal domain, until only the CLIP fragment is left, still occupying the peptide-binding groove of MHCII (Hsing and Rudensky 2005). Intermediate Ii degradation products ranging from $25 \mathrm{kDa}$ to $\sim 10 \mathrm{kDa}$ ( p25-p10) have been identified (Fig. 1B), and these accumulated when proteolytic activity of endosomes was inhibited (Neefjes and Ploegh 1992; Amigorena et al. 1995; Villadangos et al. 2000). Processing of Ii appears to be based on redundant protease activities (Costantino et al. 2008) with the exception of the cleavage of the 10 intermediate degradation product into CLIP. This requires cathepsin S (Riese et al. 1996; Driessen et al. 1999; Nakagawa et al. 1999; Shi et al. 1999) or cathepsins L and F (Nakagawa et al. 1998; Shi et al. 2000), depending on the cell type. Degradation of the remaining transmembrane fragment requires the intramembrane endopeptidase SPPL2A (Beisner et al. 2013; Bergmann et al. 2013; Schneppenheim et al. 2013). Although early studies proposed that Ii degradation is regulated and enhanced in response to DC activation (Pierre and Mellman 1998), subsequent studies proved that Ii processing is a constitutive process and not rate limiting for antigen presentation by MHCII (Villadangos et al. 2001, 2005; El-Sukkari et al. 2003; ten Broeke et al. 2010).

\section{PEPTIDE LOADING ONTO MHCII}

Newly synthesized MHCII meets its ligandspeptides that originate from the proteolysis of endocytosed antigens - in the same endocytic compartment where Ii is also degraded. In DC endosomes and phagosomes, the activity of $\mathrm{pH}$ sensitive lysosomal proteases allows hydrolysis of endocytosed antigens into peptides, whereas full degradation of peptides is prevented by multiple mechanisms (Watts 2012). Peptide loading of MHCII generally proceeds only after proteolytic processing of Ii into CLIP. As an exception, 

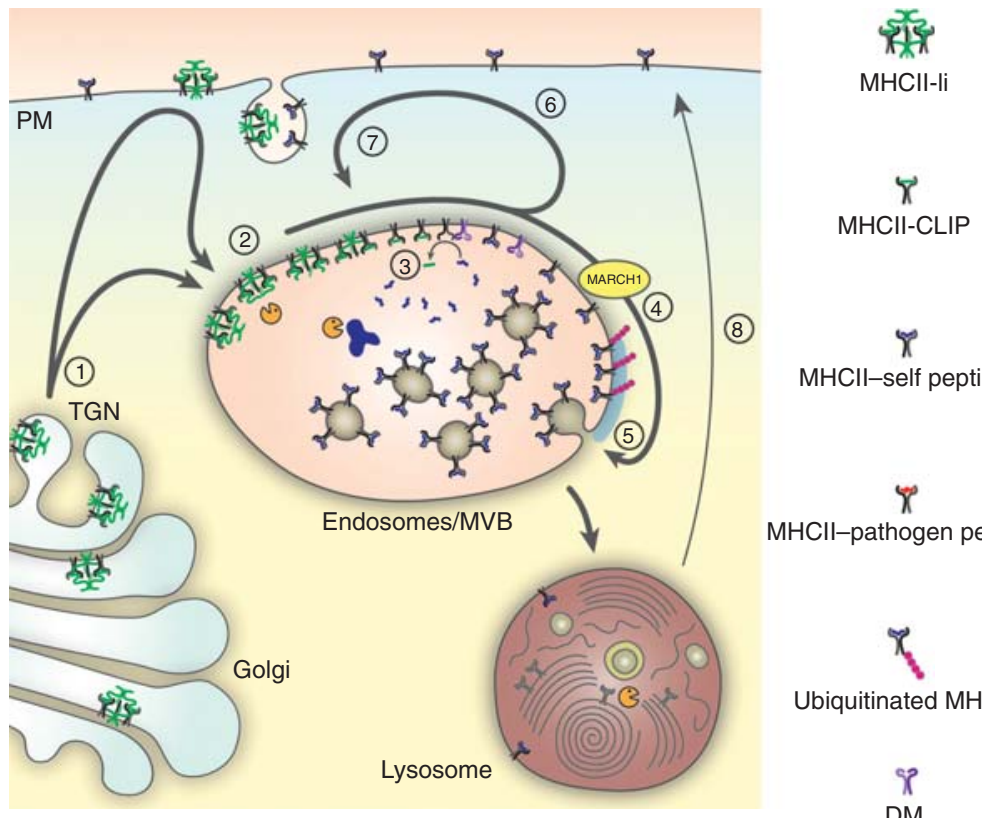

(8)

$\stackrel{x}{\text { MHCII-self peptide }}$

Yo

MHCII-pathogen peptide

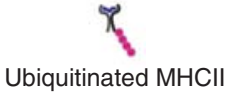

q

Activated DC

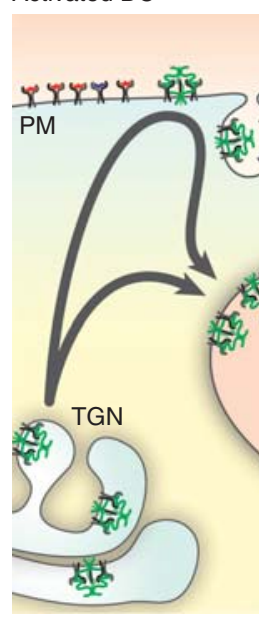

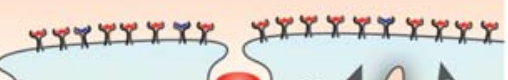

Proteases

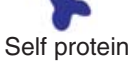

Pathogen

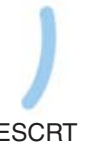

Figure 2. MHCII trafficking. The symbols are explained on the right and are equivalent to those in Figure 1. In immature DCs (top graph), newly synthesized MHC-Ii complexes are transferred via the Golgi and trans-Golgi network (TGN) to the endocytic pathway (1), either directly or via the plasma membrane, driven by leucinebased sorting signals contained within the Ii. In the endosomal system, Ii is degraded constitutively in a stepwise fashion (2), resulting in removal of the Ii-encoded sorting signals. The last remnant of the Ii, CLIP, is substituted by other peptides present within the endosomal lumen, facilitated by DM (3). Once the Ii is removed, pMHCII can be ubiquitinated by MARCH1 (4), driving its sorting to ILVs (5), probably through interactions with ESCRT. pMHCII at the endosomal delimiting membrane may also escape to the plasma membrane (6) from where it can be endocytosed (7) to encounter a new opportunity for sorting into ILVs. pMHCII that is sorted to ILVs is ultimately degraded after fusion of the MVB with the lysosome. Some MHCII may be transferred from the MVB-delimiting membrane to the lysosomal-delimiting membrane and from there to the plasma membrane to present lysosomal-generated peptides (8). In activated DCs (bottom graph), biosynthesis of MHC-Ii is temporarily up-regulated (thick arrows). Ii is processed with similar kinetics as in immature DCs, but liberated MHCII dimers are no longer ubiquitinated (9). Consequently, newly generated pMHCII is now redirected via tubular extensions from MIIC to the plasma membrane (10), whereas pMHCII that was already sorted to ILV before DC activation is still directed to lysosomes for degradation (11). 
however, peptide loading onto some MHCII haplotypes does not necessarily require full processing of Ii into CLIP (Villadangos et al. 1997). In MIICs, the exchange of CLIP for other peptides is facilitated by the nonclassical MHC molecule HLA-DM (H2-M in mice) (Denzin and Cresswell 1995; Sherman et al. 1995; Sloan et al. 1995; Kropshofer et al. 1996; Weber et al. 1996), but the degree of DM requirement for peptide loading is dependent on the MHCII isotype (Fig. 3) (van Lith et al. 2010). HLA-DM (DM) is structurally similar to MHCII but lacks the ability to bind peptides. DM can associate with MHCII to provoke dissociation of low-af-

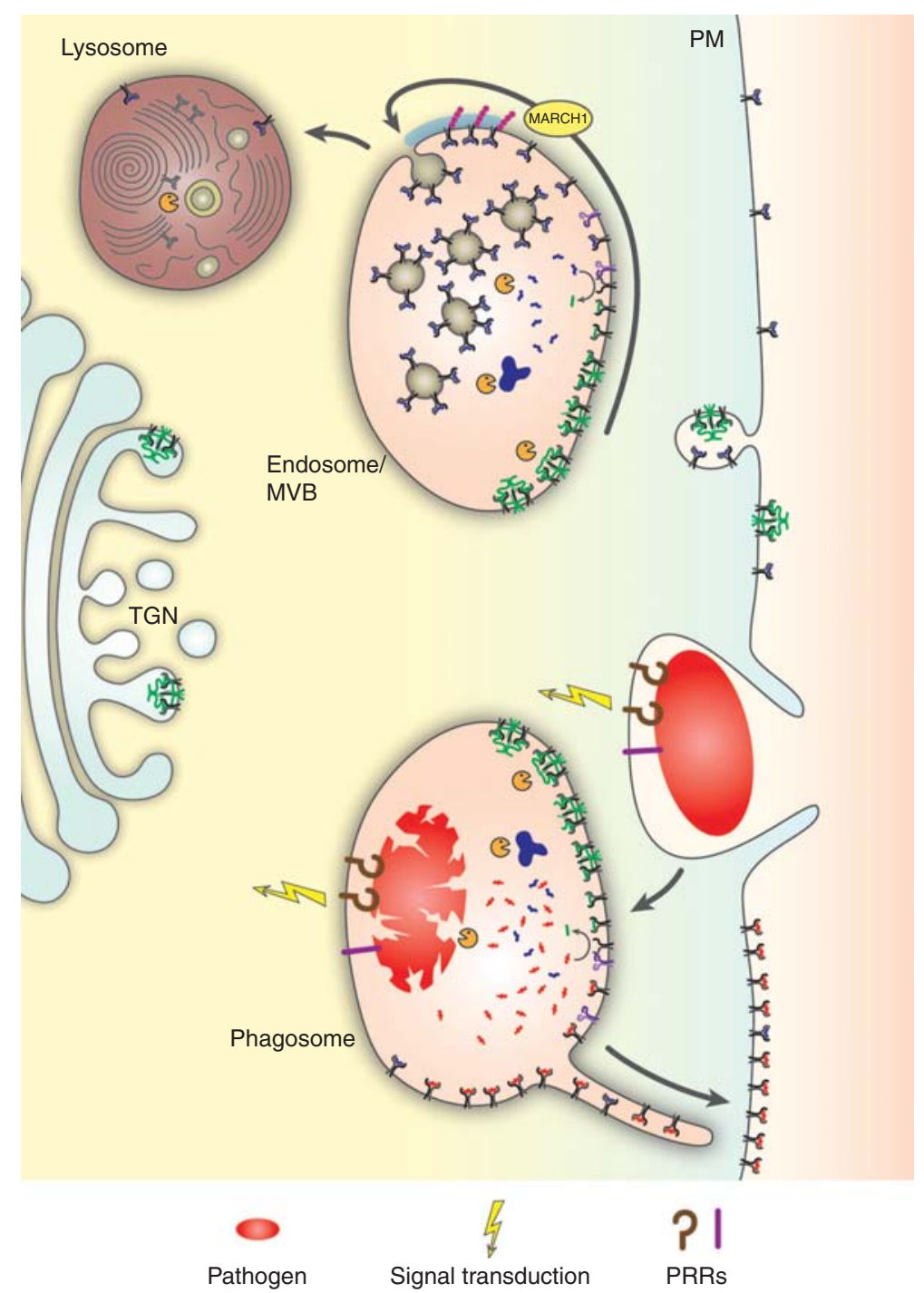

Figure 3. Autonomous function of phagosomes in MHCII processing. The symbols are similar to those in Figures 1 and 2; additional symbols are indicated at the bottom. PRR signaling from phagosomes may stimulate selective recruitment of pMHCII from those compartments to the plasma membrane (bottom structure), hypothetically through interference with MHCII ubiquitination selectively at those phagosomes. Transfer of pMHCII from pathogen-loaded phagosomes to the plasma membrane can occur unidirectionally, for example, toward immunological synapses between DC and T cells. MHCII in MIIC other than phagosomes located within the same cell may still be ubiquitinated and consequently targeted for lysosomal degradation (top structure). 
T. ten Broeke et al.

finity peptides (such as CLIP), after which another peptide can bind (Schulze and Wucherpfennig 2012). During such peptide exchange, the MHCII-binding groove is temporarily empty, a state that is rather unstable and prone to aggregation (Germain and Rinker 1993; Rabinowitz et al. 1998). DM prevents this aggregation and stabilizes empty MHCII molecules, keeping them in a peptide-receptive state (Kropshofer et al. 1997; Grotenbreg et al. 2007; Anders et al. 2011). This important DM-catalyzed editing process favors the generation of high-affinity pMHCII complexes and is facilitated by the acidic milieu in late endosomes. Another nonclassical MHC molecule involved in the regulation of MHCII antigen presentation is HLA-DO (H2-O in mice) (Denzin et al. 2005; Karlsson 2005). Like DM, HLA-DO (DO) is structurally similar to MHCII. DO forms stable complexes with DM directly after its synthesis in the ER and is transported as such to the endosomal system (Liljedahl et al. 1996). DO inhibits the peptideediting function of DM (Denzin et al. 1997; van Ham et al. 1997) particularly at mild acidic $\mathrm{pH}$ values (Kropshofer et al. 1998; Liljedahl et al. 1998; van Ham et al. 2000). DO thus inhibits DM function early in the endocytic pathway but allows peptide editing by DM in more acidic, late endocytic compartments. In immature DCs, DO is thought to increase the range of presented peptides, therewith facilitating tolerance induction to a broad range of self peptides (Yi et al. 2010). DO expression is down-regulated in activated B cells and DCs, enhancing DMcatalyzed peptide loading under inflammatory conditions (Glazier et al. 2002; Hornell et al. 2006; Draghi and Denzin 2010; Porter et al. 2011).

\section{TRAFFICKING OF PMHCII}

As a result of Ii degradation, Ii-encoded sorting signals are removed, and the nonameric MHCII-Ii complex $(\alpha \beta \mathrm{Ii})_{3}$ dissociates into MHCII $\alpha \beta$ dimers. From this point on, MHCII may either be sorted to lysosomes for degradation or be transported to the cell surface (Wubbolts et al. 1996; Théry et al. 1998). As endosomal MIICs mature, they are transported toward the cell center along microtubules (Wubbolts et al. 1999) by a dynein motor complex that is controlled by Rab7-interacting lysosomal protein (RILP) and the cholesterol sensor ORP1L (Rocha et al. 2009). In immature DCs, MHCII predominantly resides at late endosomes, which are not typical recycling compartments. Nevertheless, both MHCII-Ii and pMHCII can be transported from late endosomes to the plasma membrane via a route that is physically distinct from early endosomal recycling (Pond and Watts 1997) and with kinetics that are in agreement with other late endosomal recycling pathways (Reid and Watts 1990; Pinet et al. 1995; Lindner 2002). In a recent integrated siRNA screen on MHCII-expressing melanoma cells (Paul et al. 2011), several factors affecting recycling of MHCII to the plasma membrane have been identified, including the small GTPase ARL14/ ARF7. This GTPase recruits the effector protein ARF7EP onto MIICs, which acts as a receptor for the actin-based motor protein myosin $1 \mathrm{E}$, putatively driving transport of vesicles containing MHCII from MIIC to the plasma membrane. In maturing DCs, transport of MHCII is mediated via membrane tubules that radiate out from the MIIC toward the plasma membrane, and this pathway depends on an intact microtubule network (Kleijmeer et al. 2001; Boes et al. 2002, 2003; Chow et al. 2002; Vyas et al. 2007; van Nispen tot Pannerden et al. 2010). MHCII, DM, and LAMP1 are not enriched in these tubules relative to the vacuolar endosomes from which they derive, suggesting that this pathway may not require active recruitment but is entered by default (Kleijmeer et al. 2001). This is in agreement with the finding that traffic of MHCII to the cell surface does not rely on sorting information encoded by its cytosolic domains (Théry et al. 1998). Upon arrival at the cell surface, pMHCII complexes can be endocytosed only to recycle again to the plasma membrane via early endocytic compartments (Reid and Watts 1990, 1992). The latter pathway is extremely rapid (Reid and Watts 1990) and potentially may provide opportunities for MHCII to also sample antigens that differ from those found in the late endosomal compartments, thereby contributing to the diversity in antigen presentation 
(Pinet et al. 1995; Lindner and Unanue 1996; Griffin et al. 1997; Pathak and Blum 2000). MHCII peptide loading at these alternate locations may differ for the requirements of DM or Ii (Vergelli et al. 1997; Villadangos et al. 2000) and is more prominent for some MHCII isotypes (van Lith et al. 2010).

The mechanism(s) for endocytosis of pMHCII are not well understood. Internalization was negatively affected by truncation of both the cytosolic domains of the $\alpha$ and $\beta$ chains (Pinet et al. 1995), indicating active recruitment and a role of cytoplasmic domains in endocytic uptake. A conserved di-leucine motif in the cytosolic domain of the $\beta$ chain was proposed to have a role in pMHCII endocytosis (Zhong et al. 1997; Simonsen et al. 1999), although this motif lacks upstream negatively charged amino acids that are generally thought to be required for interaction with clathrin adaptors (Bonifacino and Traub 2003). We and others proposed that endocytosis of MHCII is facilitated, to a limited extent, by ubiquitination of the cytoplasmic domain of the MHCII $\beta$ chain (Shin et al. 2006; van Niel et al. 2006). It should be noted, however, that the assays used in these and other studies (Reid and Watts 1990, 1992) on MHCII endocytosis did not discriminate between MHCII-Ii and pMHCII, nor did they correct for recycling of endocytosed MHCII. Other studies could not confirm a role for ubiquitination in endocytosis of pMHCII (Matsuki et al. 2007; Walseng et al. 2010a). Interference with ubiquitination-dependent endosomal sorting may increase recycling, and this can also impact on the readout of endocytosis assays. These experimental problems were tackled in more recent experiments, from which we concluded that ubiquitination has little if any effect on the endocytosis rate of pMHCII ( $\mathrm{T}$ ten Broeke, R Wubbolts, W Stoorvogel, et al., unpubl.). In contrast to MHCII-Ii complexes, pMHCII is endocytosed via clathrin- and dynamin-independent pathway(s), possibly involving SWAP-70-regulated RhoA/ RhoB (Ocana-Morgner et al. 2009) or Arf6and Rab35-dependent mechanism(s) (Walseng et al. 2008). MHCII is found in detergent-resistant membrane domains (DRMs) (Anderson et al. 2000; Karacsonyi et al. 2004; Rodgers and
Smith 2005), and endocytosis of MHCII was severely hampered after treatment of cells with Filipin, a cholesterol-sequestering agent (Knorr et al. 2009). Perhaps pMHCII uses the clathrinindependent carrier (GLIC)/GPI-AP-enriched early endosomal compartment (GEEC) pathway, an endocytosis route that is also used by lipid raft-associated molecules like GPI-linked proteins and cholera toxin B (Mayor and Pagano 2007; Howes et al. 2010). Furthermore, tetraspanin-enriched microdomains have been implicated in clustering and routing of MHCII from the plasma membrane (Hammond et al. 1998; Engering and Pieters 2001; Kropshofer et al. 2002; Zilber et al. 2005; Poloso et al. 2006; Unternaehrer et al. 2007). Tetraspanins belong to a family of proteins that span the membrane four times and are palmitoylated, a posttranslational modification that stimulates lateral partitioning into protein/lipid domains (Kovalenko et al. 2004; Yáñez-Mó et al. 2009). Most tetraspanins contain motifs for clathrin-mediated endocytosis (Berditchevski and Odintsova 2007) that potentially could assist the internalization of domain-associated molecules such as pMHCII. In conclusion, although several mechanisms for endocytosis of pMHCII have been proposed, the exact pathways and dynamics that apply for different cell systems remain largely undefined.

\section{SORTING OF MHCII AT MVBS}

Endosomes generate intraluminal vesicles (ILVs) that progressively increase in number during endosome maturation, giving rise to an eminent multivesicular morphology. Hence, this type of late endosomes is also referred to as a multivesicular endosome or multivesicular body (MVB) (Piper and Katzmann 2007). Membrane proteins that are targeted to ILVs are ultimately transferred to lysosomes for degradation. Transfer to ILVs also terminates signaling of plasma membrane receptors, as exemplified by receptor tyrosine kinases and G-protein-coupled receptors (Sorkin and von Zastrow 2009). As an alternative for a lysosomal destination, MVBs may fuse with the plasma membrane, thereby releasing their ILVs as exosomes in the extracellular space (Raposo and 
T. ten Broeke et al.

Stoorvogel 2013). Whereas one set of MVBs serves as a sorting station for membrane proteins to lysosomes, another set of functionally distinct MVBs is rather destined to release exosomes. In DCs, sorting of MHCII at MVBs into exosomes is, in contrast to lysosomal targeting, independent of MHCII ubiquitination and rather correlates with incorporation into tetraspanin-containing complexes (Buschow et al. 2009). Exosome release was stimulated when DCs engaged antigen-specific $\mathrm{CD}^{+} \mathrm{T}$ cells (Buschow et al. 2009). Released exosomes can be recruited by such T cells or bystander DCs in an LFA-1-dependent manner (Segura et al. 2007; Nolte-'t Hoen et al. 2009), and in this way, directly or indirectly, contribute to T-cell activation (Théry et al. 2002a,b). Relative to mature DCs, immature DCs release little MHCII with exosomes, and by far most of their MVBs are destined to fuse with lysosomes. At equilibrium, $\sim 60 \%$ of all cellular MHCII in immature DCs are located at MVBs, of which $\sim 80 \%$ are at ILVs, consistent with active recruitment of MHCII into ILVs (Kleijmeer et al. 2001; ten Broeke et al. 2011). Indeed, the density of MHCII (molecules/micrometers squared) is much higher on ILVs than on the MVB-delimiting membrane (Kleijmeer et al. 2001). We and others reported that MHCII in immature DCs is ubiquitinated at a unique lysine residue at position 225 in the cytoplasmic domain of MHCII $\beta$, and this modification was identified as a key regulator of MHCII surface expression and stability (Ohmura-Hoshino et al. 2006; Shin et al. 2006; van Niel et al. 2006; Matsuki et al. 2007). To a lesser extent, MHCII $\alpha$ may also be ubiquitinated, but this was reported only for model cell lines that were cotransfected with MHCII and MARCH ligases (Lapaque et al. 2009b). In immature DCs, surface expression of a K225 mutant of MHCII $\beta$ was dramatically increased in comparison to wild-type MHCII $\beta$ (Shin et al. 2006; van Niel et al. 2006; Matsuki et al. 2007), with the major cause being that sorting at MVBs into ILVs was $>20$-fold less efficient (van Niel et al. 2006). Ubiquitination-driven cargo sorting and ILV formation at endosomes are facilitated by the endosomal sorting complex required for transport
(ESCRT) (Raiborg and Stenmark 2009; Hurley 2010; Henne et al. 2011, 2013; Piper et al. 2013). Consistent with its generic role, it can be expected that the ESCRT machinery also drives sorting of ubiquitinated MHCII into ILVs. Indeed, several ESCRT-associated components, including Tollip, were identified to influence MHCII traffic (Paul et al. 2011). In support for a role for ESCRT, we found that MHCII in DCs is, indeed, enriched in the flat clathrin/ESCRT-0-coated lattices at MIICs (van Niel et al. 2008). ILV formation can proceed only after ESCRT disassembly, and this requires ATP hydrolysis by the class I AAA ATPase Vps4 complex (Hill and Babst 2012). Expression of a dominant-negative mutant of VPS4 interfered with MHCII sorting ( T ten Broeke, R Wubbolts, W Stoorvogel, et al., unpubl.). MIICs are composed not only of MVBs but also of multilamellar compartments. The latter contain abundant MHCII-labeled internal membrane sheets, and high-resolution three-dimensional (3D) analysis of these compartments suggests that they represent lysosomal compartments with MHCII trapped on their inner membranes, possibly in the process of being degraded (Murk et al. 2004).

Activation of conventional DCs (cDCs) strongly reduces ubiquitination of MHCII, intervening with its targeting to ILVs (Shin et al. 2006; van Niel et al. 2006; De Gassart et al. 2008; Walseng et al. 2010b). Reduction in ILV targeting leads to rerouting of pMHCII to the cell surface, possibly by default (see above), therewith elevating expression levels at the plasma membrane. In maturing cDCs, pMHCII that had already been sorted to ILVs before $\mathrm{CDC}$ activation is still targeted to and degraded in lysosomes, while only newly generated pMHCII is selectively stabilized and transferred to the plasma membrane (ten Broeke et al. 2011). Synthesis of MHCII is shut off in fully matured cDCs. As a consequence, pMHCII that are stably displayed on mature $\mathrm{cDCs}$ are predominantly generated directly after pathogen contact. This creates a "snapshot" for presentation of those peptides that are present directly after pathogen contact, therewith optimizing the presentation of "foreign peptides" relative to "self peptides." Unlike activated cDCs, activated plasmacytoid 
DCs ( pDCs) carry on synthesizing as well as ubiquitinating MHCII, allowing continuation of the sampling and presentation of acquired endogenous (late) viral antigens in their activated state (Young et al. 2008).

Ubiquitination of MHCII is largely driven by MARCH1 (Matsuki et al. 2007; De Gassart et al. 2008), a member of the family of MARCH E3 ligases (Nathan and Lehner 2009). Besides MHCII, the costimulatory molecule CD86 is also targeted by MARCH1-driven ubiquitination to lysosomes (Baravalle et al. 2011). The molecular mechanism for attenuating MHCII or CD86 ubiquitination in activated $\mathrm{cDCs}$ is not entirely clear. Although MARCH1 has a half-life of $<30 \mathrm{~min}$ (Jabbour et al. 2009), its transcription is turned off only $>8 \mathrm{~h}$ after DC activation (De Gassart et al. 2008; Young et al. 2008). The relatively late onset of transcription regulation suggests that additional mechanisms are responsible for the rapid interference $(<1 \mathrm{~h})$ with MHCII ubiquitination in response to maturation stimuli. One mechanism could involve deubiquitination, although MHCII-specific deubiquitinating enzyme(s) have not yet been identified. Another potential regulatory factor is CD83, which is highly expressed on mature DCs and was shown to bind MARCH1, sequestering it from MHCII (Tze et al. 2011). Yet other undiscovered regulatory mechanisms may provide additional modes to regulate ubiquitination of MHCII. The pivotal role of MARCH1 in regulating MHCII-mediated antigen presentation is further illustrated by observations that the anti-inflammatory cytokine IL-10 enhances MARCH1 expression (Thibodeau et al. 2008; Baravalle et al. 2011; Tze et al. 2011), thereby promoting MHCII degradation at immunesuppressive conditions. The central role of $\mathrm{MHC}$ ubiquitination in antigen presentation is also illustrated by reports on how certain pathogens can suppress immunity by targeting this system (Ishido et al. 2009; Lapaque et al. 2009a). The discovery of viral E3-ubiquitin ligases that down-modulate surface expression of MHCI have, in fact, also helped the identification of MARCH ligases that regulate MHCII surface expression (Bartee et al. 2004; Ohmura-Hoshino et al. 2006). In addition to MARCH1, other
MARCH ligases can also ubiquitinate MHCII. In MARCH1 knockout mice, ubiquitination of MHCII was fully suppressed in B cells but only partially in DCs (Matsuki et al. 2007), suggesting some redundant ligase activity in DCs. MARCH8/c-MIR was able to reduce MHCII surface expression when overexpressed (Ohmura-Hoshino et al. 2006), indicating overlapping specificity with MARCH1. Although MARCH1 seems to play a more prominent role in controlling pMHCII traffic in DCs (De Gassart et al. 2008), it cannot be excluded that the two ligases act at distinct sites, for example, at the plasma membrane and at the endosomal membrane, leaving dissimilar sorting signatures. In this regard, it was recently shown that sorting of MHCII is highly dependent on the length of the conjugated ubiquitin chain (Ma et al. 2012). Specificities of MARCH ligases may differ for distinct MHCII isotypes (Jahnke et al. 2012). The biological relevance of ubiquitination-driven MHCII traffic has also been investigated in vivo and has generated some dispute. Knock-in mice for a ubiquitination mutant of MHCII showed dysfunction of DCs similar to that of MARCH1 knockout mice (Ohmura-Hoshino et al. 2009). Others concluded that ubiquitin-dependent control of MHCII localization is dispensable for antigen presentation and antibody production (McGehee et al. 2011). In the latter study, mice in which endogenous MHCII was replaced by GFP-tagged wildtype MHCII were compared with knock-in mice for a K225 ubiquitination mutant of GFP-tagged MHCII. These animals performed equally well in generating $\mathrm{CD} 4^{+} \mathrm{T}$ cells and antibody titers in response to model antigens at DC-activating conditions. However, it should be noted that at DC-activating conditions, ubiquitination of wild-type MHCII is also absent. As explained above, it can be expected that ubiquitination of MHCII rather serves to prevent antigen presentation by nonactivated DCs. In a recent in vivo study, it was found that MARCH1-mediated ubiquitination of MHCII in dendritic cells promotes selection of natural regulatory T cells (Oh et al. 2013), again consistent with a role in the prevention of autoimmune responses. 
T. ten Broeke et al.

\section{MVB DYNAMICS AND MHCII PEPTIDE LOADING}

As discussed above, degradation of Ii in the endocytic system liberates MHCII $\alpha \beta$ dimers from the $(\alpha \beta \mathrm{Ii})_{3}$ nonameric complex and allows MHCII peptide loading. It has been debated whether peptide loading occurs preferentially at the endosomal-delimiting membrane or at ILVs. DM facilitates MHCII peptide loading and is present at the MVB-delimiting membrane and ILVs (Kleijmeer et al. 2001), and both sites provide access to the peptide pool generated in the MVB lumen. In transfected HEK293 cells with experimentally swollen MVBs, MHCII and DM were shown by fluorescence resonance energy transfer (FRET) to interact primarily at ILVs, suggesting that peptide loading onto MHCII may preferentially occur at ILVs (Zwart et al. 2005). In this case, a pathway should exist for pMHCII to travel back from ILVs to the endosomal-delimiting membrane from where it could then reach the plasma membrane. Such a pathway, also referred to as "back-fusion" or retrofusion of ILVs, was also proposed to explain the disappearance of the MVB during DC maturation (Kleijmeer et al. 2001) and to provide a source of membrane needed for the formation of MIIC-associated tubules in maturing DCs (Boes et al. 2002, 2003; Chow et al. 2002; Vyas et al. 2007). More recently, however, it was shown that such membrane tubules can be generated as a consequence of homotypic endosome fusion (Skjeldal et al. 2012), which is accelerated in maturing DCs (van Nispen tot Pannerden et al. 2010). ILV back-fusion has, in fact, never been convincingly recorded in live cells nor in vitro, and therefore remains hypothetical, despite a proposed involvement of lysobisphosphatidic acid, Tsg101, or Alix (Falguières et al. 2009). Several lines of more convincing evidence support the idea that MHCII peptide loading occurs at the endosomal-delimiting membrane, in contrast to ILVs. First, MHCII failed to sort to ILVs in cathepsinS-deficient intestinal epithelial or professional antigen-presenting cells (Beers et al. 2005; Boes et al. 2005). Cathepsin S is required for the degradation of Ii (p10), and hence also for subse- quent ubiquitination of MHCII (see above). Thus, Ii is already processed into CLIP and ready for peptide loading at the endosomal-delimiting membrane. Also, DM is abundantly present at MVB-delimiting membranes (Kleijmeer et al. 2001); thus, all essential requirements for peptide loading are at hand at this location. This is consistent with our observation that ubiquitinated MHCII is in a SDS-stable peptide-loaded complex (van Niel et al. 2006). After recruitment by the ESCRT machinery, ubiquitinated cargo is deubiquitinated before incorporation into ILVs (Henne et al 2011). Thus, MHCII peptide loading occurs before or concomitant with ubiquitination, before ILV incorporation. MHCII peptide loading and ubiquitinaton are not necessarily mechanistically linked, and the sequence of events could merely be dictated by differences in kinetics. A second indication for MHCII peptide loading at the endosomal-delimiting membrane is that loading of wild-type MHCII and mutant K225 MHCII were equally efficient (Shin et al. 2006; van Niel et al. 2006), and that antigen presentation was unaffected in ubiquitination-deficient MHCII knock-in mice (McGehee et al. 2011). Third, interference with MHCII sorting at MVBs with a dominant-negative mutant of VPS4 also did not affect peptide loading ( $\mathrm{T}$ ten Broeke, R Wubbolts, W Stoorvogel, et al., unpubl.). Finally, in a recent study, we showed directly that maturing DCs predominantly used newly synthesized MHCII for antigen presentation rather than MHCII that was synthesized before DC activation (ten Broeke et al. 2011). This directly excludes a ubiquitination-dependent cycle of MHCII through ILVs, because ubiquitination is absent (van Niel et al. 2006) and MVB formation diminished upon DC activation (Kleijmeer et al. 2001). These observations also argue against the idea that MHCII at ILV in immature DCs may serve as a "storage pool" that can be recruited in response to DC activation. For maturing DCs, it seems even undesirable to recruit a preexisting pool of pMHCII from ILVs, because this was generated before pathogen contact, and presentation of self peptides loaded into these MHCII molecules at inflammatory conditions may provoke autoimmunity. In this line of thought, and con- 
sistent with our data (ten Broeke et al. 2011), it would rather be favorable when all pMHCII at ILVs would be irreversibly destined for degradation in the lysosome, irrespective of DC activation.

\section{AUTONOMOUS PHAGOSOMES}

After DC activation, only a minority of MHCII molecules truly display pathogen-derived peptides (Trombetta and Mellman 2005). This poses a conceptual problem that has not yet been fully resolved. How does the immune system prevent the activation of self-reactive $\mathrm{T}$ cells by activated DCs that in addition to foreign peptides also display self peptides in the context of MHCII? Part of the answer came with the concept that mature DCs present a "snapshot" of their antigenic environment at the time of activation. In response to DC activation by pathogens, the selectivity of loading microbial-derived antigens over self peptides is achieved through transient up-regulation followed by shutoff of MHCII synthesis in combination with a change in the sorting behavior of newly synthesized MHCII at the endocytic tract (Villadangos et al 2005; ten Broeke et al. 2011). Another way to increase selectivity in antigen presentation is the formation of pMHCII microdomains that are preformed within phagosomes and maintained upon arrival at the DC plasma membrane (Bosch et al. 2013). Further specificity may be achieved through autonomous control by phagosomes in contributing pMHCII for presentation, meaning that antigens are preferentially presented by MHCII when originating from antigen-carrying particles that also stimulate DC-activating receptors from within that same compartment (Blander and Medzhitov 2006; Hoffmann et al. 2012). This idea is supported by the observations that TLR2 (Underhill et al. 1999) and TLR4 (Husebye et al. 2010; Mantegazza et al. 2012) can be recruited to and signal from phagosomes. TLR delivery to phagosomes requires the clathrin adaptor AP-3, and local signaling facilitates pMHCII recruitment from phagosomes for presentation at the plasma membrane (Mantegazza et al. 2012). Phagosome-specific TLR signaling pathways have not been specified, but besides TLRs may also involve local MHCII molecules (Inaba et al. 1998; Blander and Medzhitov 2006). Recruitment of TLR and/or MHCII to phagosomes may also involve the Arf-like GTPase Arl8b and its downstream effector, the homotypic fusion- and vacuolar protein-sorting (HOPS) complex, analogous to their role in functional targeting of CD1 to phagosomes (Garg et al. 2011). Clearly, pMHCII can also be recruited to the plasma membrane from endocytic compartments other than phagosomes, but recruitment from PAMP-carrying phagosomes may prevail. To achieve immune evasion, pathogens like Salmonella (Lapaque et al. 2009a) and Francisella tularensis (Wilson et al. 2009) stimulate the host system to ubiquitinate MHCII, stimulating transfer to lysosomes rather than to the plasma membrane. Phagosomes that carry less sophisticated pathogens might stabilize MHCII molecules through local interference with ubiquitination. Maintenance of MHCII ubiquitination in endocytic compartments other than phagosomes within the same cell would enhance selectivity in MHCII presentation of pathogen-derived peptides. Transfer of pMHCII from pathogen-loaded phagosomes to the plasma membrane can occur unidirectionally, for example, toward immunological synapse between DC and T cells (Boes et al. 2002; Keller et al. 2007), applying yet another layer of specificity.

\section{CONCLUDING REMARKS AND FUTURE DIRECTIONS}

The mechanisms that regulate MHCII antigen presentation by DCs are instrumental in directing specificity in adaptive immune responses. Although MHCII is constitutively synthesized and loaded with peptide, newly formed pMHCII complexes are efficiently displayed only upon DC activation. Surface exposure and lifetime of pMHCII are determined by sorting at MVBs. Ubiquitination drives MHCII into ILVs, resulting in transfer to and degradation in lysosomes. Ubiquitination of MHCII is regulated, possibly differentially depending on the subcellular location, by largely unknown mecha- 
nisms. Clearly, further research is required to understand how selectivity in peptide presentation by MHCII is achieved, particularly with regard to the mechanism(s) of the silencing of MHCII ubiquitination in activated DCs. The potential role of phagosome autonomy herein also needs to be explored. Such knowledge may be instrumental to design more efficient vaccination strategies, for example, through physical coupling of vaccine antigens to immune adjuvants. Disclosure of mechanisms by which some bacteria and viruses avoid immune surveillance by enhancing MHCII traffic to lysosomes may help development of novel medicines toward such pathogens. Finally, whether failure of proper regulation of $\mathrm{MHCII}$ ubiquitination can contribute to the development of autoimmune diseases also needs to be investigated.

\section{ACKNOWLEDGMENTS}

We thank Guillaume van Niel, Marca Wauben, Lisette Nijland, and Birol Cabukusta, as well as other laboratory members and collaborators for their contributions to our work and stimulating discussions. We apologize to all colleagues whose work could not be cited because of space limitations. We thank Utrecht University for support and funding.

\section{REFERENCES}

${ }^{*}$ Reference is also in this collection.

Amigorena S, Savina A. 2010. Intracellular mechanisms of antigen cross presentation in dendritic cells. Curr Opin Immunol 22: 109-117.

Amigorena S, Webster P, Drake J, Newcomb J, Cresswell P, Mellman I. 1995. Invariant chain cleavage and peptide loading in major histocompatibility complex class II vesicles. J Exp Med 181: 1729-1741.

Anders A, Call MJ, Schulze MED, Fowler KD, Schubert DA, Seth NP, Sundberg EJ, Wucherpfennig KW. 2011. HLADM captures partially empty HLA-DR molecules for catalyzed removal of peptide. Nat Immunol 12: 54-61.

Anderson MS, Miller J. 1992. Invariant chain can function as a chaperone protein for class II major histocompatibility complex molecules. Proc Natl Acad Sci 89: 22822286.

Anderson HA, Roche PA. 1998. Phosphorylation regulates the delivery of MHC class II invariant chain complexes to antigen processing compartments. J Immunol 160: 4850-4858.
Anderson HA, Bergstralh DT, Kawamura T, Blauvelt A, Roche PA. 1999. Phosphorylation of the invariant chain by protein kinase C Regulates MHC class II trafficking to antigen-processing compartments. J Immunol 163: 5435-5443.

Anderson HA, Hiltbold EM, Roche PA. 2000. Concentration of MHC class II molecules in lipid rafts facilitates antigen presentation. Nat Immunol 1: 156-162.

Arunachalam B, Lamb CA, Cresswell P. 1994. Transport properties of free and MHC class ll-associated oligomers containing different isoforms of human invariant chain. Int Immunol 6: 439-451.

Ashman JB, Miller J. 1999. A role for the transmembrane domain in the trimerization of the MHC Class II-associated invariant chain. J Immunol 163: 2704-2712.

Baravalle G, Park H, McSweeney M, Ohmura-Hoshino M, Matsuki Y, Ishido S, Shin JS. 2011. Ubiquitination of CD86 is a key mechanism in regulating antigen presentation by dendritic cells. J Immunol 187: 2966-2973.

Bartee E, Mansouri M, Hovey Nerenberg BT, Gouveia K, Fruh K. 2004. Downregulation of major histocompatibility complex class I by human ubiquitin ligases related to viral immune evasion proteins. J Virol 78: 1109-1120.

Beers C, Burich A, Kleijmeer MJ, Griffith JM, Wong P, Rudensky AY. 2005. Cathepsin S controls MHC class IImediated antigen presentation by epithelial cells in vivo. J Immunol 174: 1205-1212.

Beisner DR, Langerak P, Parker AE, Dahlberg C, Otero FJ, Sutton SE, Poirot L, Barnes W, Young MA, Niessen S, et al. 2013. The intramembrane protease Sppl2a is required for B cell and DC development and survival via cleavage of the invariant chain. J Exp Med 210: 23-30.

Benaroch P, Yilla M, Raposo G, Ito K, Miwa K, Geuze HJ, Ploegh HL. 1995. How MHC class II molecules reach the endocytic pathway. EMBO J 14: 37-49.

Berditchevski F, Odintsova E. 2007. Tetraspanins as regulators of protein trafficking. Traffic 8: 89-96.

Bergmann H, Yabas M, Short A, Miosge L, Barthel N, Teh CE, Roots CM, Bull KR, Jeelall Y, Horikawa K, et al. 2013. B cell survival, surface BCR and BAFFR expression, CD74 metabolism, and $\mathrm{CD}^{-}$dendritic cells require the intramembrane endopeptidase SPPL2A. J Exp Med 210: $31-$ 40.

Bevec T, Stoka V, Pungercic G, Dolenc I, Turk V. 1996. Major histocompatibility complex class II-associated p41 invariant chain fragment is a strong inhibitor of lysosomal cathepsin L. J Exp Med 183: 1331-1338.

Bijlmakers MJ, Benaroch P, Ploegh HL. 1994. Mapping functional regions in the lumenal domain of the class II-associated invariant chain. J Exp Med 180: 623-629.

Bikoff EK, Huang LY, Episkopou V, van Meerwijk J, Germain RN, Robertson EJ. 1993. Defective major histocompatibility complex class II assembly, transport, peptide acquisition, and $\mathrm{CD}^{+}{ }^{+} \mathrm{T}$ cell selection in mice lacking invariant chain expression. J Exp Med 177: 1699-1712.

Blander JM, Medzhitov R. 2006. Toll-dependent selection of microbial antigens for presentation by dendritic cells. Nature 440: 808-812.

Blum JS, Wearsch PA, Cresswell P. 2013. Pathways of antigen processing. Annu Rev Immunol 31: 443-473. 
Boes M, Cerny J, Massol R, Op dB, Kirchhausen T, Chen J, Ploegh HL. 2002. T-cell engagement of dendritic cells rapidly rearranges MHC class II transport. Nature 418: 983-988.

Boes M, Bertho N, Cerny J, Op den Brouw M, Kirchhausen T, Ploegh H. 2003. T cells induce extended class II MHC compartments in dendritic cells in a Toll-like receptordependent manner. J Immunol 171: 4081-4088.

Boes M, van der Wel N, Peperzak V, Kim Y, Peters PJ, Ploegh H. 2005. In vivo control of endosomal architecture by class II-associated invariant chain and cathepsin S. Eur J Immunol 35: 2552-2562.

Bonifacino JS, Traub LM. 2003. Signals for sorting of transmembrane proteins to endosomes and lysosomes. Annu Rev Biochem 72: 395-447.

Bosch B, Heipertz EL, Drake JR, Roche PA. 2013. MHC class II-peptide complexes arrive at the plasma membrane in cholesterol-rich microclusters. J Biol Chem 288: 13236 13242.

Bremnes B, Madsen T, Gedde-Dahl M, Bakke O. 1994. An LI and ML motif in the cytoplasmic tail of the MHC-associated invariant chain mediate rapid internalization. $J$ Cell Sci 107: 2021-2032.

Busch R, Cloutier I, Sekaly RP, Hammerling GJ. 1996. Invariant chain protects class II histocompatibility antigens from binding intact polypeptides in the endoplasmic reticulum. EMBO J 15: 418-428.

Buschow SI, Hoen ENMN, van Niel G, Pols MS, ten Broeke T, Lauwen M, Ossendorp F, Melief CJM, Raposo G, Wubbolts R, et al. 2009. MHC II in dendritic cells is targeted to lysosomes or $\mathrm{T}$ cell-induced exosomes via distinct multivesicular body pathways. Traffic 10: 1528-1542.

Castellino F, Germain RN. 1995. Extensive trafficking of MHC class II-invariant chain complexes in the endocytic pathway and appearance of peptide-loaded class II in multiple compartments. Immunity 2: 73-88.

Charron DJ, Aellen-Schulz M, Geme JS III, Erlich HA, McDevitt HO. 1983. Biochemical characterization of an invariant polypeptide associated with Ia antigens in human and mouse. Mol Immunol 20: 21-32.

Chicz RM, Urban RG, Lane WS, Gorga JC, Stern LJ, Vignali DAA, Strominger JL. 1992. Predominant naturally processed peptides bound to HLA-DR1 are derived from MHC-related molecules and are heterogeneous in size. Nature 358: 764-768.

Choi NM, Majumder P, Boss JM. 2011. Regulation of major histocompatibility complex class II genes. Curr Opin Immunol 23: 81-87.

Chow A, Toomre D, Garrett W, Mellman I. 2002. Dendritic cell maturation triggers retrograde MHC class II transport from lysosomes to the plasma membrane. Nature 418: 988-994.

Cools N, Ponsaerts P, Van Tendeloo VFI, Berneman ZN. 2007. Balancing between immunity and tolerance: An interplay between dendritic cells, regulatory $\mathrm{T}$ cells, and effector T cells. J Leukoc Biol 82: 1365-1374.

Costantino CM, Hang HC, Kent SC, Hafler DA, Ploegh HL. 2008. Lysosomal cysteine and aspartic proteases are heterogeneously expressed and act redundantly to initiate human invariant chain degradation. I Immunol 180: 2876-2885.
Cresswell P, Ackerman AL, Giodini A, Peaper DR, Wearsch PA. 2005. Mechanisms of MHC class I-restricted antigen processing and cross-presentation. Immunol Rev 207: $145-157$.

Crotzer VL, Blum JS. 2010. Autophagy and adaptive immunity. Immunology 131: 9-17.

De Gassart A, Camosseto V, Thibodeau J, Ceppi M, Catalan N, Pierre P, Gatti E. 2008. MHC class II stabilization at the surface of human dendritic cells is the result of maturation-dependent MARCH I down-regulation. Proc Natl Acad Sci 105: 3491-3496.

Dengjel J, Schoor O, Fischer R, Reich M, Kraus M, Müller M, Kreymborg K, Altenberend F, Brandenburg J, Kalbacher H, et al. 2005. Autophagy promotes MHC class II presentation of peptides from intracellular source proteins. Proc Natl Acad Sci 102: 7922-7927.

Denzin LK, Cresswell P. 1995. HLA-DM induces clip dissociation from MHC class II $\alpha \beta$ dimers and facilitates peptide loading. Cell 82: 155-165.

Denzin LK, Sant'Angelo DB, Hammond C, Surman MJ, Cresswell P. 1997. Negative regulation by HLA-DO of MHC class II-restricted antigen processing. Science 278: 106-109.

Denzin LK, Fallas JL, Prendes M, Yi W. 2005. Right place, right time, right peptide: DO keeps DM focused. Immunol Rev 207: 279-292.

Draghi NA, Denzin LK. 2010. H2-O, a MHC class II-like protein, sets a threshold for B-cell entry into germinal centers. Proc Natl Acad Sci 107: 16607-16612.

Driessen C, Bryant RAR, Lennon-Duménil A, Villadangos JA, Bryant PW, Shi G, Chapman HA, Ploegh HL. 1999. Cathepsin $\mathrm{S}$ controls the trafficking and maturation of MHC Class II molecules in dendritic cells. J Cell Biol 147: $775-790$.

Dugast M, Toussaint H, Dousset C, Benaroch P. 2005. AP2 clathrin adaptor complex, but not AP1, controls the access of the major histocompatibility complex (MHC) class II to endosomes. J Biol Chem 280: 19656-19664.

Elliott EA, Drake JR, Amigorena S, Elsemore J, Webster P, Mellman I, Flavell RA. 1994. The invariant chain is required for intracellular transport and function of major histocompatibility complex class II molecules. J Exp Med 179: 681-694.

El-Sukkari D, Wilson NS, Hakansson K, Steptoe RJ, Grubb A, Shortman K, Villadangos JA. 2003. The protease inhibitor Cystatin C is differentially expressed among dendritic cell populations, but does not control antigen presentation. J Immunol 171: 5003-5011.

Engering A, Pieters J. 2001. Association of distinct tetraspanins with MHC class II molecules at different subcellular locations in human immature dendritic cells. Int Immunol 13: 127-134.

Falguières T, Luyet P, Gruenberg J. 2009. Molecular assemblies and membrane domains in multivesicular endosome dynamics. Exp Cell Res 315: 1567-1573.

Freisewinkel IM, Schenck K, Koch N. 1993. The segment of invariant chain that is critical for association with major histocompatibility complex class II molecules contains the sequence of a peptide eluted from class II polypeptides. Proc Natl Acad Sci 90: 9703-9706. 
T. ten Broeke et al.

Garg S, Sharma M, Ung C, Tuli A, Barral D, Hava D, Veerapen N, Besra G, Hacohen N, Brenner M. 2011. Lysosomal trafficking, antigen presentation, and microbial killing are controlled by the Arf-like GTPase Arl8b. Immunity 35: $182-193$.

Gedde-Dahl M, Freisewinkel I, Staschewski M, Schenck K, Koch N, Bakke O. 1997. Exon 6 is essential for invariant chain trimerization and induction of large endosomal structures. J Biol Chem 272: 8281-8287.

Geppert T, Lipsky P. 1985. Antigen presentation by interferon- $\gamma$-treated endothelial cells and fibroblasts: Differential ability to function as antigen-presenting cells despite comparable Ia expression. J Immunol 135: 3750-3762.

Germain RN, Rinker AG. 1993. Peptide binding inhibits protein aggregation of invariant-chain free class II dimers and promotes surface expression of occupied molecules. Nature 363: 725-728.

Geuze HJ. 1998. The role of endosomes and lysosomes in MHC class II functioning. Immunol Today 19: 282-287.

Glazier KS, Hake SB, Tobin HM, Chadburn A, Schattner EJ, Denzin LK. 2002. Germinal center B cells regulate their capability to present antigen by modulation of HLA-DO. J Exp Med 195: 1063-1069.

Griffin J, Chu R, Harding C. 1997. Early endosomes and a late endocytic compartment generate different peptideclass II MHC complexes via distinct processing mechanisms. J Immunol 158: 1523-1532.

Grotenbreg GM, Nicholson MJ, Fowler KD, Wilbuer K, Octavio L, Yang M, Chakraborty AK, Ploegh HL, Wucherpfennig KW. 2007. Empty class II major histocompatibility complex created by peptide photolysis establishes the role of DM in peptide association. J Biol Chem 282: $21425-$ 21436.

Guermonprez P, Valladeau J, Zitvogel L, Thery C, Amigorena S. 2002. Antigen presentation and T cell stimulation by dendritic cells. Annu Rev Immunol 20: 621-667.

Hammond C, Denzin LK, Pan M, Griffith JM, Geuze HJ, Cresswell P. 1998. The tetraspan protein CD82 is a resident of MHC class II compartments where it associates with HLA-DR, -DM, and -DO molecules. J Immunol 161: 3282-3291.

Henne W, Buchkovich N, Emr S. 2011. The ESCRT pathway. Dev Cell 21: 77-91.

* Henne WM, Stenmark H, Emr SD. 2013. Molecular mechanisms of the membrane sculpting ESCRT pathway. Cold Spring Harb Perpsect Biol 5: a016766.

Hill CP, Babst M. 2012. Structure and function of the membrane deformation AAA ATPase Vps4. Biochim Biophys Acta 1823: $172-181$

Hoffmann E, Kotsias F, Visentin G, Bruhns P, Savina A, Amigorena S. 2012. Autonomous phagosomal degradation and antigen presentation in dendritic cells. Proc Natl Acad Sci 109: 14556-14561.

Hofmann MW, Höning S, Rodionov D, Dobberstein B, von Figura K, Bakke O. 1999. The leucine-based sorting motifs in the cytoplasmic domain of the invariant chain are recognized by the clathrin adaptors AP1 and AP2 and their medium chains. J Biol Chem 274: 36153-36158.

Hornell TMC, Burster T, Jahnsen FL, Pashine A, Ochoa MT, Harding JJ, Macaubas C, Lee AW, Modlin RL, Mellins ED. 2006. Human dendritic cell expression of HLA-DO is subset specific and regulated by maturation. J Immunol 176: $3536-3547$.

Howes MT, Mayor S, Parton RG. 2010. Molecules, mechanisms, and cellular roles of clathrin-independent endocytosis. Curr Opin Cell Biol 22: 519-527.

Hsing LC, Rudensky AY. 2005. The lysosomal cysteine proteases in MHC class II antigen presentation. Immunol Rev 207: 229-241.

Hurley JH. 2010. The ESCRT complexes. Crit Rev Biochem Mol Biol 45: 463-487.

Husebye H, Aune MH, Stenvik J, Samstad E, Skjeldal F, Halaas $\varnothing$, Nilsen NJ, Stenmark H, Latz E, Lien E, et al. 2010. The Rab11a GTPase controls Toll-like receptor 4induced activation of interferon regulatory factor-3 on phagosomes. Immunity 33: 583-596.

Inaba K, Turley S, Yamaide F, Iyoda T, Mahnke K, Inaba M, Pack M, Subklewe M, Sauter B, Sheff D, et al. 1998. Efficient presentation of phagocytosed cellular fragments on the major histocompatibility complex class II products of dendritic cells. J Exp Med 188: 2163-2173.

Ishido S, Goto E, Matsuki Y, Ohmura-Hoshino M. 2009. E3 ubiquitin ligases for MHC molecules. Curr Opin Immunol 21: 78-83

Jabbour M, Campbell EM, Fares H, Lybarger L. 2009. Discrete domains of MARCH1 mediate its localization, functional interactions, and posttranscriptional control of expression. J Immunol 183: 6500-6512.

Jabrane-Ferrat N, Nekrep N, Tosi G, Esserman L, Peterlin BM. 2003. MHC class II enhanceosome: How is the class II transactivator recruited to DNA-bound activators? Int Immunol 15: 467-475.

Jahnke M, Trowsdale J, Kelly AP. 2012. Structural requirements for recognition of major histocompatibility complex class II by membrane-associated RING-CH (MARCH) Protein E3 ligases. J Biol Chem 287: 2877928789.

Joffre O, Nolte MA, Spörri R, Reis e Sousa C. 2009. Inflammatory signals in dendritic cell activation and the induction of adaptive immunity. Immunol Rev 227: 234-247.

Joffre OP, Segura E, Savina A, Amigorena S. 2012. Crosspresentation by dendritic cells. Nat Rev Immunol 12: $557-569$.

Jones PP, Murphy DB, Hewgill D, McDevitt HO. 1979. Detection of a common polypeptide chain in I-A and I-E sub-region immunoprecipitates. Mol Immunol 16: $51-60$.

Karacsonyi C, Knorr R, Fülbier A, Lindner R. 2004. Association of major histocompatibility complex II with cholesterol- and sphingolipid-rich membranes precedes peptide loading. J Biol Chem 279: 34818-34826.

Karlsson L. 2005. DM and DO shape the repertoire of peptide-MHC-class-II complexes. Curr Opin Immunol 17: 65-70.

Keller AM, Groothuis TA, Veraar EAM, Marsman M, de Buy Wenniger LM, Janssen H, Neefjes J, Borst J. 2007. Costimulatory ligand CD70 is delivered to the immunological synapse by shared intracellular trafficking with MHC class II molecules. Proc Natl Acad Sci 104: 5989-5994.

Kleijmeer MJ, Morkowski S, Griffith JM, Rudensky AY, Geuze HJ. 1997. Major histocompatibility complex class II compartments in human and mouse B lymphoblasts 
represent conventional endocytic compartments. $J$ Cell Biol 139: 639-649.

Kleijmeer M, Ramm G, Schuurhuis D, Griffith J, Rescigno M, Ricciardi-Castagnoli P, Rudensky AY, Ossendorp F, Melief CJM, Stoorvogel W, et al. 2001. Reorganization of multivesicular bodies regulates MHC class II antigen presentation by dendritic cells. J Cell Biol 155: 53-64.

Knorr R, Karacsonyi C, Lindner R. 2009. Endocytosis of MHC molecules by distinct membrane rafts. J Cell Sci 122: $1584-1594$.

Koch N, Lauer W, Habicht J, Dobberstein B. 1987. Primary structure of the gene for the murine Ia antigen-associated invariant chains (Ii). An alternatively spliced exon encodes a cysteine-rich domain highly homologous to a repetitive sequence of thyroglobulin. EMBO J 6: $1677-$ 1683.

Koch N, Lipp J, Pessara U, Schenck K, Wraight C, Dobberstein B. 1989. MHC class II invariant chains in antigen processing and presentation. Trends Biochem Sci 14:383386.

Kondylis V, van Nispen tot Pannerden HE, van Dijk S, ten Broeke T, Wubbolts R, Geerts WJ, Seinen C, Mutis T, Heijnen HF. 2013. Endosome-mediated autophagy: An unconventional MIIC-driven autophagic pathway operational in dendritic cells. Autophagy 9: 861-880.

Kovalenko OV, Yang X, Kolesnikova TV, Hemler ME. 2004 Evidence for specific tetraspanin homodimers: Inhibition of palmitoylation makes cysteine residues available for cross-linking. Biochem J 377: 407-417.

Kreisel D, Richardson SB, Li W, Lin X, Kornfeld CG, Sugimoto S, Hsieh C, Gelman AE, Krupnick AS. 2010. Cutting edge: MHC class II expression by pulmonary nonhematopoietic cells plays a critical role in controlling local inflammatory responses. J Immunol 185: 38093813.

Kropshofer H, Vogt AB, Moldenhauer G, Hammer J, Blum JS, Hämmerling GJ. 1996. Editing of the HLA-DR-peptide repertoire by HLA-DM. EMBO J 15: 6144-6154.

Kropshofer H, Arndt SO, Moldenhauer G, Hämmerling GJ, Vogt AB. 1997. HLA-DM acts as a molecular chaperone and rescues empty HLA-DR molecules at lysosomal $\mathrm{pH}$. Immunity 6: 293-302.

Kropshofer H, Vogt AB, Thery C, Armandola EA, Li B, Moldenhauer G, Amigorena S, Hammerling GJ. 1998. A role for HLA-DO as a co-chaperone of HLA-DM in peptide loading of MHC class II molecules. EMBO J 17: 2971-2981.

Kropshofer H, Spindeldreher S, Rohn TA, Platania N, Grygar C, Daniel N, Wolpl A, Langen H, Horejsi V, Vogt AB. 2002. Tetraspan microdomains distinct from lipid rafts enrich select peptide-MHC class II complexes. Nat Immunol 3: 61-68.

Krupnick AS, Gelman AE, Barchet W, Richardson S, Kreisel FH, Turka LA, Colonna M, Patterson GA, Kreisel D. 2005. Cutting edge: Murine vascular endothelium activates and induces the generation of allogeneic $\mathrm{CD}^{+} 25^{+} \mathrm{Foxp}^{+}$ regulatory T cells. J Immunol 175: 6265-6270.

Kvist S, Wiman K, Claesson L, Peterson PA, Dobberstein B. 1982. Membrane insertion and oligomeric assembly of HLA-DR histocompatibility antigens. Cell 29: 61-69.
Lamb C, Cresswell P. 1992. Assembly and transport properties of invariant chain trimers and HLA-DR-invariant chain complexes. J Immunol 148: 3478-3482.

Lapaque N, Hutchinson JL, Jones DC, Méresse S, Holden DW, Trowsdale J, Kelly AP. 2009a. Salmonella regulates polyubiquitination and surface expression of MHC class II antigens. Proc Natl Acad Sci 106: 14052-14057.

Lapaque N, Jahnke M, Trowsdale J, Kelly AP. 2009b. The HLA-DR $\alpha$ chain is modified by polyubiquitination. $J$ Biol Chem 284: 7007-7016.

Liljedahl M, Kuwana T, Fung-Leung WP, Jackson MR, Peterson PA, Karlsson L. 1996. HLA-DO is a lysosomal resident which requires association with HLA-DM for efficient intracellular transport. EMBO J 15: 4817-4824.

Liljedahl M, Winqvist O, Surh CD, Wong P, Ngo K, Teyton L, Peterson PA, Brunmark A, Rudensky AY, Fung-Leung W, et al. 1998. Altered antigen presentation in mice lacking H2-O. Immunity 8: 233-243.

Lindner R. 2002. Transient surface delivery of invariant chain-MHC II complexes via endosomes: A quantitative study. Traffic 3: 133-146.

Lindner R, Unanue ER. 1996. Distinct antigen MHC class II complexes generated by separate processing pathways. EMBO J 15: 6910-6920.

Liu S, Marks MS, Brodsky FM. 1998. A dominant-negative clathrin mutant differentially affects trafficking of molecules with distinct sorting motifs in the class II major histocompatibility complex (MHC) pathway. J Cell Biol 140: $1023-1037$.

Lutz MB, Rovere P, Kleijmeer MJ, Rescigno M, Assmann CU, Oorschot VM, Geuze HJ, Trucy J, Demandolx D, Davoust J, et al. 1997. Intracellular routes and selective retention of antigens in mildly acidic cathepsin D/lysosome-associated membrane protein-1/MHC class II-positive vesicles in immature dendritic cells. J Immunol 159: 3707-3716.

Ma JK, Platt MY, Eastham-Anderson J, Shin J, Mellman I. 2012. MHC class II distribution in dendritic cells and B cells is determined by ubiquitin chain length. Proc Natl Acad Sci 109: 8820-8827.

Maldonado RA, von Andrian UH. 2010. How tolerogenic dendritic cells induce regulatory $\mathrm{T}$ cells. Adv Immunol 108: $111-165$.

Mantegazza A, Guttentag S, El-Benna J, Sasai M, Iwasaki A, Shen H, Laufer T, Marks M. 2012. Adaptor Protein-3 in dendritic cells facilitates phagosomal Toll-like receptor signaling and antigen presentation to $\mathrm{CD} 4^{+} \mathrm{T}$ cells. Immunity 36: 782-794.

Mantegazza AR, Magalhaes JG, Amigorena S, Marks MS. 2013. Presentation of phagocytosed antigens by MHC class I and II. Traffic 14: 135-152.

Marks MS, Blum JS, Cresswell P. 1990. Invariant chain trimers are sequestered in the rough endoplasmic reticulum in the absence of association with HLA class II antigens. J Cell Biol 111: 839-855.

Marks MS, Germain RN, Bonifacino JS. 1995. Transient aggregation of major histocompatibility complex class II chains during assembly in normal spleen cells. J Biol Chem 270: 10475-10481.

Matsuki Y, Ohmura-Hoshino M, Goto E, Aoki M, MitoYoshida M, Uematsu M, Hasegawa T, Koseki H, Ohara 
T. ten Broeke et al.

O, Nakayama M, et al. 2007. Novel regulation of MHC class II function in B cells. EMBO J 26: 846-854.

Mayor S, Pagano RE. 2007. Pathways of clathrin-independent endocytosis. Nat Rev Mol Cell Biol 8: 603-612.

McCormick PJ, Martina JA, Bonifacino JS. 2005. Involvement of clathrin and AP-2 in the trafficking of MHC class II molecules to antigen-processing compartments. Proc Natl Acad Sci 102: 7910-7915.

McGehee AM, Strijbis K, Guillen E, Eng T, Kirak O, Ploegh HL. 2011. Ubiquitin-dependent control of class II MHC localization is dispensable for antigen presentation and antibody production. PLoS ONE 6: e18817.

Menges M, Rössner S, Voigtländer C, Schindler H, Kukutsch NA, Bogdan C, Erb K, Schuler G, Lutz MB. 2002. Repetitive injections of dendritic cells matured with tumor necrosis factor $\alpha$ induce antigen-specific protection of mice from autoimmunity. J Exp Med 195: 15-22.

Mihelič M, Doberšek A, Gunčar G, Turk D. 2008. Inhibitory fragment from the $\mathrm{p} 41 \mathrm{form}$ of invariant chain can regulate activity of cysteine cathepsins in antigen presentation. J Biol Chem 283: 14453-14460.

Mulder DJ, Pooni A, Mak N, Hurlbut DJ, Basta S, Justinich CJ. 2011. Antigen presentation and MHC class II expression by human esophageal epithelial cells: Role in eosinophilic esophagitis. Am J Pathol 178: 744-753.

Murk JAN, Lebbink MN, Humbel BM, Geerts WJC, Griffith JM, Langenberg DML, Verreck FAW, Verkleij AJ, Koster AJ, Geuze HJ, et al. 2004. 3-D structure of multilaminar lysosomes in antigen presenting cells reveals trapping of MHC II on the internal membranes. Traffic 5: 936-945.

Nakagawa T, Roth W, Wong P, Nelson A, Farr A, Deussing J, Villadangos JA, Ploegh H, Peters C, Rudensky AY. 1998. Cathepsin L: Critical role in Ii degradation and CD4 T cell selection in the thymus. Science 280: 450-453.

Nakagawa TY, Brissette WH, Lira PD, Griffiths RJ, Petrushova N, Stock J, McNeish JD, Eastman SE, Howard ED, Clarke SRM, et al. 1999. Impaired invariant chain degradation and antigen presentation and diminished collagen-induced arthritis in cathepsin S null mice. Immunity 10: $207-217$.

Nathan JA, Lehner PJ. 2009. The trafficking and regulation of membrane receptors by the RING-CH ubiquitin E3 ligases. Exp Cell Res 315: 1593-1600.

Neefjes JJ, Ploegh HL. 1992. Inhibition of endosomal proteolytic activity by leupeptin blocks surface expression of MHC class II molecules and their conversion to SDS resistance $\alpha \beta$ heterodimers in endosomes. $E M B O J$ 11: 411-416.

Neefjes JJ, Stollorz V, Peters PJ, Geuze HJ, Ploegh HL. 1990. The biosynthetic pathway of MHC class II but not class I molecules intersects the endocytic route. Cell 61: 171183.

Neefjes J, Jongsma MLM, Paul P, Bakke O. 2011. Towards a systems understanding of MHC class I and MHC class II antigen presentation. Nat Rev Immunol 11: 823-836.

Nolte-'t Hoen ENM, Buschow SI, Anderton SM, Stoorvogel W, Wauben MHM. 2009. Activated T cells recruit exosomes secreted by dendritic cells via LFA-1. Blood 113: 1977-1981.
Ocana-Morgner C, Wahren C, Jessberger R. 2009. SWAP-70 regulates RhoA/RhoB-dependent MHCII surface localization in dendritic cells. Blood 113: 1474-1482.

Odorizzi CG, Trowbridge IS, Xue L, Hopkins CR, Davis CD, Collawn JF. 1994. Sorting signals in the MHC class II invariant chain cytoplasmic tail and transmembrane region determine trafficking to an endocytic processing compartment. J Cell Biol 126: 317-330.

Oh J, Wu N, Baravalle G, Cohn B, Ma J, Lo B, Mellman I, Ishido S, Anderson M, Shin JS. 2013. MARCH1-mediated MHCII ubiquitination promotes dendritic cell selection of natural regulatory T cells. J Exp Med 210: 10691077.

Ohmura-Hoshino M, Matsuki Y, Aoki M, Goto E, Mito M, Uematsu M, Kakiuchi T, Hotta H, Ishido S. 2006. Inhibition of MHC class II expression and immune responses by c-MIR. J Immunol 177: 341-354.

Ohmura-Hoshino M, Matsuki Y, Mito-Yoshida M, Goto E, Aoki-Kawasumi M, Nakayama M, Ohara O, Ishido S. 2009. Cutting edge: Requirement of MARCH-I-mediated MHC II ubiquitination for the maintenance of conventional dendritic cells. J Immunol 183: 6893-6897.

O'Sullivan DM, Noonan D, Quaranta V. 1987. Four Ia invariant chain forms derive from a single gene by alternate splicing and alternate initiation of transcription/translation. J Exp Med 166: 444-460.

Owen MJ, Kissonerghis AM, Lodish HF, Crumpton MJ. 1981. Biosynthesis and maturation of HLA-DR antigens in vivo. J Biol Chem 256: 8987-8993.

Pathak SS, Blum JS. 2000. Endocytic recycling is required for the presentation of an exogenous peptide via MHC class II molecules. Traffic 1: 561-569.

Paul P, van den Hoorn T, Jongsma MM, Bakker M, Hengeveld R, Janssen L, Cresswell P, Egan D, van Ham M, ten Brinke A, et al. 2011. A genome-wide multidimensional RNAi screen reveals pathways controlling MHC class II antigen presentation. Cell 145: 268-283.

Peters PJ, Neefjes JJ, Oorschot V, Ploegh HL, Geuze HJ. 1991. Segregation of MHC class II molecules from MHC class I molecules in the Golgi complex for transport to lysosomal compartments. Nature 349: 669-676.

Peterson M, Miller J. 1992. Antigen presentation enhanced by the alternatively spliced invariant chain gene product p41. Nature 357: 596-598.

Pierre P, Mellman I. 1998. Developmental regulation of invariant chain proteolysis controls MHC class II trafficking in mouse dendritic cells. Cell 93: 1135-1145.

Pieters J, Horstmann H, Bakke O, Griffiths G, Lipp J. 1991. Intracellular transport and localization of major histocompatibility complex class II molecules and associated invariant chain. J Cell Biol 115: 1213-1223.

Pieters J, Bakke O, Dobberstein B. 1993. The MHC class II associated invariant chain contains two endosomal targeting signals within its cytoplasmic tail. J Cell Sci 106: 831-846.

Pinet V, Vergelli M, Martini R, Bakke O, Long EO. 1995. Antigen presentation mediated by recycling of surface HLA-DR molecules. Nature 375: 603-606.

Piper RC, Katzmann DJ. 2007. Biogenesis and function of multivesicular bodies. Annu Rev Cell Dev Biol 23: 519547. 
* Piper RC, Dikic I, Lukacs G. 2014. Ubiquitin-dependent sorting in endocytosis. Cold Spring Harb Perspect Biol doi: $10.1101 /$ cshperspect.a016808.

Pober JS, Collins T, Gimbrone MA, Cotran RS, Gitlin JD, Fiers W, Clayberger C, Krensky AM, Burakoff SJ, Reiss CS. 1983. Lymphocytes recognize human vascular endothelial and dermal fibroblast Ia antigens induced by recombinant immune interferon. Nature 305: 726-729.

Poloso NJ, Denzin LK, Roche PA. 2006. CDw78 defines MHC class II-peptide complexes that require Ii chaindependent lysosomal trafficking, not localization to a specific tetraspanin membrane microdomain. J Immunol 177: $5451-5458$

Pond L, Watts C. 1997. Characterization of transport of newly assembled, T-cell-stimulatory MHC class II-peptide complexes from MHC class II compartments to the cell surface. J Immunol 159: 543-553.

Pond L, Watts C. 1999. Functional early endosomes are required for maturation of major histocompatibility complex class II molecules in human B lymphoblastoid cells. J Biol Chem 274: 18049-18054.

Porter GW, Yi W, Denzin LK. 2011. TLR agonists downregulate $\mathrm{H} 2-\mathrm{O}$ in $\mathrm{CD} 8 \alpha^{-}$dendritic cells. J Immunol 187: $4151-4160$.

Rabinowitz JD, Vrljic M, Kasson PM, Liang MN, Busch R, Boniface JJ, Davis MM, McConnell HM. 1998. Formation of a highly peptide-receptive state of class II MHC. Immunity 9: 699-709.

Raiborg C, Stenmark H. 2009. The ESCRT machinery in endosomal sorting of ubiquitylated membrane proteins. Nature 458: 445-452.

Raposo G, Stoorvogel W. 2013. Extracellular vesicles: Exosomes, microvesicles, and friends. J Cell Biol 200: $373-$ 383.

Reid PA, Watts C. 1990. Cycling of cell-surface MHC glycoproteins through primaquine-sensitive intracellular compartments. Nature 346: 655-657.

Reid PA, Watts C. 1992. Constitutive endocytosis and recycling of major histocompatibility complex class II glycoproteins in human B-lymphoblastoid cells. Immunology 77: $539-542$.

Reis e Sousa C. 2006. Dendritic cells in a mature age. Nat Rev Immunol 6: 476-483.

Reith W, LeibundGut-Landmann S, Waldburger J. 2005. Regulation of MHC class II gene expression by the class II transactivator. Nat Rev Immunol 5: 793-806.

Riberdy JM, Newcomb JR, Surman MJ, Barbosat JA, Cresswell P. 1992. HLA-DR molecules from an antigen-processing mutant cell line are associated with invariant chain peptides. Nature 360: 474-477.

Riese RJ, Wolf PR, Brömme D, Natkin LR, Villadangos JA, Ploegh HL, Chapman HA. 1996. Essential role for cathepsin S in MHC class II-associated invariant chain processing and peptide loading. Immunity 4: 357-366.

Rocha N, Kuijl C, van der Kant R, Janssen L, Houben D, Janssen H, Zwart W, Neefjes J. 2009. Cholesterol sensor ORP1L contacts the ER protein VAP to control Rab7RILP-p150Glued and late endosome positioning. J Cell Biol 185: 1209-1225.
Roche PA, Cresswell P. 1990. Invariant chain association with HLA-DR molecules inhibits immunogenic peptide binding. Nature 345: 615-618.

Roche PA, Cresswell P. 1991. Proteolysis of the class II-associated invariant chain generates a peptide binding site in intracellular HLA-DR molecules. Proc Natl Acad Sci 88: 3150-3154.

Roche PA, Teletski CL, Stang E, Bakke O, Long EO. 1993. Cell surface HLA-DR-invariant chain complexes are targeted to endosomes by rapid internalization. Proc Natl Acad Sci 90: 8581-8585.

Rodgers W, Smith K. 2005. Properties of glycolipid-enriched membrane rafts in antigen presentation. Crit Rev Immunol 25: 19-30.

Rodionov DG, Bakke O. 1998. Medium chains of adaptor complexes AP-1 and AP-2 recognize leucine-based sorting signals from the invariant chain. J Biol Chem 273: 6005-6008.

Romagnoli P, Germain RN. 1994. The CLIP region of invariant chain plays a critical role in regulating major histocompatibility complex class II folding, transport, and peptide occupancy. J Exp Med 180: 1107-1113.

Romieu-Mourez R, François M, Boivin M, Stagg J, Galipeau J. 2007. Regulation of MHC class II expression and antigen processing in murine and human mesenchymal stromal cells by IFN- $\gamma$, TGF- $\beta$, and cell density. J Immunol 179: $1549-1558$.

Rudd CE, Bodmer JG, Bodmer WF, Crumpton MJ. 1985. HLA-D region antigen-associated invariant polypeptides as revealed by two-dimensional gel analysis. Glycosylation and structural inter-relationships. J Biol Chem 260: 1927-1936.

Rudensky AY, Preston-Hurlburt P, Hong S, Barlow A, Janeway CA. 1991. Sequence analysis of peptides bound to MHC class II molecules. Nature 353: 622-627.

Salamero J, Borgne RL, Saudrais C, Goud B, Hoflack B. 1996. Expression of major histocompatibility complex class II molecules in HeLa cells promotes the recruitment of AP-1 Golgi-specific assembly proteins on Golgi membranes. J Biol Chem 271: 30318-30321.

Santambrogio L, Potolicchio I, Fessler SP, Wong S, Raposo G, Strominger JL. 2005. Involvement of caspase-cleaved and intact adaptor protein 1 complex in endosomal remodeling in maturing dendritic cells. Nat Immunol 6: $1020-1028$.

Schaiff WT, Hruska KA, McCourt DW, Green M, Schwartz BD. 1992. HLA-DR associates with specific stress proteins and is retained in the endoplasmic reticulum in invariant chain negative cells. J Exp Med 176: 657-666.

Schmidt SV, Nino-Castro AC, Schultze JL. 2012. Regulatory dendritic cells: There is more than just immune activation. Front Immunol 3: 274.

Schneppenheim J, Dressel R, Hüttl S, Lüllmann-Rauch R, Engelke M, Dittmann K, Wienands J, Eskelinen E, Hermans-Borgmeyer I, Fluhrer R, et al. 2013. The intramembrane protease SPPL2a promotes B cell development and controls endosomal traffic by cleavage of the invariant chain. J Exp Med 210: 41-58.

Schulze ME, Wucherpfennig KW. 2012. The mechanism of HLA-DM induced peptide exchange in the MHC class II antigen presentation pathway. Curr Opin Immunol 24: $105-111$. 
T. ten Broeke et al.

Segura E, Villadangos JA. 2011. A modular and combinatorial view of the antigen cross-presentation pathway in dendritic cells. Traffic 12: 1677-1685.

Segura E, Guérin C, Hogg N, Amigorena S, Théry C. 2007. $\mathrm{CD}^{+}$dendritic cells use LFA- 1 to capture MHC-peptide complexes from exosomes in vivo. J Immunol 179: 1489-1496.

Sekaly RP, Tonnelle C, Strubin M, Mach B, Long EO. 1986. Cell surface expression of class II histocompatibility antigens occurs in the absence of the invariant chain. J Exp Med 164: 1490-1504.

Sette A, Ceman S, Kubo RT, Sakaguchi K, Appella E, Hunt DF, Davis TA, Michel H, Shabanowitz J, Rudersdorf R. 1992. Invariant chain peptides in most HLA-DR molecules of an antigen-processing mutant. Science 258: 1801-1804.

Sherman MA, Weber DA, Jensen PE. 1995. DM enhances peptide binding to class II MHC by release of invariant chain-derived peptide. Immunity 3: 197-205.

Shi G, Villadangos JA, Dranoff G, Small C, Gu L, Haley KJ, Riese R, Ploegh HL, Chapman HA. 1999. Cathepsin S required for normal MHC class II peptide loading and germinal center development. Immunity 10: 197-206.

Shi G, Bryant RAR, Riese R, Verhelst S, Driessen C, Li Z, Bromme D, Ploegh HL, Chapman HA. 2000. Role for cathepsin $\mathrm{F}$ in invariant chain processing and major histocompatibility complex class II peptide loading by macrophages. J Exp Med 191: 1177-1186.

Shin JS, Ebersold M, Pypaert M, Delamarre L, Hartley A, Mellman I. 2006. Surface expression of MHC class II in dendritic cells is controlled by regulated ubiquitination. Nature 444: 115-118.

Simonsen A, Pedersen KW, Nordeng TW, von der Lippe A, Stang E, Long EO, Bakke O. 1999. Polarized transport of MHC class II molecules in Madin-Darby canine kidney cells is directed by a leucine-based signal in the cytoplasmic tail of the $\beta$-chain. J Immunol 163: 2540-2548.

Skjeldal FM, Strunze S, Bergeland T, Walseng E, Gregers TF, Bakke O. 2012. The fusion of early endosomes induces molecular-motor-driven tubule formation and fission. $J$ Cell Sci 125: 1910-1919.

Sloan VS, Cameron P, Porter G, Gammon M, Amaya M, Mellins E, Zaller DM. 1995. Mediation by HLA-DM of dissociation of peptides from HLA-DR. Nature 375: 802-806.

Sorkin A, von Zastrow M. 2009. Endocytosis and signalling: Intertwining molecular networks. Nat Rev Mol Cell Biol 10: 609-622.

Spiro R, Quaranta V. 1989. The invariant chain is a phosphorylated subunit of class II molecules. J Immunol 143: 2589-2594.

Steinman RM, Hawiger D, Nussenzweig MC. 2003. Tolerogenic dendritic cells. Annu Rev Immunol 21: 685-711.

Strubin M, Berte C, Mach B. 1986. Alternative splicing and alternative initiation of translation explain the four forms of the Ia antigen-associated invariant chain. $E M B O J 5$ : 3483-3488.

Tan JKH, O’Neill HC. 2005. Maturation requirements for dendritic cells in $\mathrm{T}$ cell stimulation leading to tolerance versus immunity. J Leukoc Biol 78: 319-324. ten Broeke T, de Graaff A, van't Veld EM, Wauben MH, Stoorvogel W, Wubbolts R. 2010. Trafficking of MHC class II in dendritic cells is dependent on but not regulated by degradation of its associated invariant chain. Traffic 11: 324-331.

ten Broeke T, van Niel G, Wauben MHM, Wubbolts R, Stoorvogel W. 2011. Endosomally stored MHC class II does not contribute to antigen presentation by dendritic cells at inflammatory conditions. Traffic 12: 1025-1036.

Teyton L, O'Sullivan D, Dickson PW, Lotteau V, Sette A, Fink P, Peterson PA. 1990. Invariant chain distinguishes between the exogenous and endogenous antigen presentation pathways. Nature 348: 39-44.

Théry C, Brachet V, Regnault A, Rescigno M, Ricciardi-Castagnoli P, Bonnerot C, Amigorena S. 1998. MHC class II transport from lysosomal compartments to the cell surface is determined by stable peptide binding, but not by the cytosolic domains of the $\alpha$ - and $\beta$-chains. J Immunol 161: $2106-2113$.

Théry C, Duban L, Segura E, Veron P, Lantz O, Amigorena S. 2002a. Indirect activation of naive $\mathrm{CD} 4^{+} \mathrm{T}$ cells by dendritic cell-derived exosomes. Nat Immunol 3: 1156-1162.

Théry C, Zitvogel L, Amigorena S. 2002b. Exosomes: Composition, biogenesis and function. Nat Rev Immunol 2: 569-579.

Thibodeau J, Bourgeois-Daigneault M, Huppé G, Tremblay J, Aumont A, Houde M, Bartee E, Brunet A, Gauvreau M, de Gassart A, et al. 2008. Interleukin-10-induced MARCH1 mediates intracellular sequestration of MHC class II in monocytes. Eur J Immunol 38: 1225-1230.

Trombetta ES, Mellman I. 2005. Cell biology of antigen processing in vitro and in vivo. Annu Rev Immunol 23: 975-1028.

Tze LE, Horikawa K, Domaschenz H, Howard DR, Roots CM, Rigby RJ, Way DA, Ohmura-Hoshino M, Ishido S, Andoniou CE, et al. 2011. CD83 increases MHC II and CD86 on dendritic cells by opposing IL-10-driven MARCH1-mediated ubiquitination and degradation. $J$ Exp Med 208: 149-165.

Underhill DM, Ozinsky A, Hajjar AM, Stevens A, Wilson CB, Bassetti M, Aderem A. 1999. The Toll-like receptor 2 is recruited to macrophage phagosomes and discriminates between pathogens. Nature 401: 811-815.

Unternaehrer JJ, Chow A, Pypaert M, Inaba K, Mellman I. 2007. The tetraspanin CD9 mediates lateral association of MHC class II molecules on the dendritic cell surface. Proc Natl Acad Sci 104: 234-239.

van Ham SM, Tjin EPM, Lillemeier BF, Grüneberg U, van Meijgaarden KE, Pastoors L, Verwoerd D, Tulp A, Canas B, Rahman D, et al. 1997. HLA-DO is a negative modulator of HLA-DM-mediated MHC class II peptide loading. Curr Biol 7: 950-957.

van Ham M, van Lith M, Lillemeier B, Tjin E, Grüneberg U, Rahman D, Pastoors L, van Meijgaarden K, Roucard C, Trowsdale J, et al. 2000. Modulation of the major histocompatibility complex class II-associated peptide repertoire by human histocompatibility leukocyte antigen (Hla)-Do. J Exp Med 191: 1127-1136.

van Lith M, McEwen-Smith RM, Benham AM. 2010. HLADP, HLA-DQ, and HLA-DR have different requirements for invariant chain and HLA-DM. J Biol Chem 285: 40800-40808. 
van Niel G, Wubbolts R, ten Broeke T, Buschow SI, Ossendorp FA, Melief CJ, Raposo G, van Balkom BW, Stoorvogel W. 2006. Dendritic cells regulate exposure of MHC class II at their plasma membrane by oligoubiquitination. Immunity 25: 885-894.

van Niel G, Wubbolts R, Stoorvogel W. 2008. Endosomal sorting of MHC class II determines antigen presentation by dendritic cells. Curr Opin Cell Biol 20: 437-444.

van Nispen tot Pannerden, HE, Geerts WJ, Kleijmeer MJ, Heijnen HFG. 2010. Spatial organization of the transforming MHC class II compartment. Biol Cell 102: 581-591.

Vergelli M, Pinet V, Vogt AB, Kalbus M, Malnati M, Riccio P, Long EO, Martin R. 1997. HLA-DR-restricted presentation of purified myelin basic protein is independent of intracellular processing. Eur J Immunol 27: 941-951.

Villadangos JA, Riese RJ, Peters C, Chapman HA, Ploegh HL. 1997. Degradation of mouse invariant chain: Roles of cathepsins $S$ and D and the influence of major histocompatibility complex polymorphism. J Exp Med 186: 549560.

Villadangos JA, Driessen C, Shi G, Chapman HA, Ploegh HL. 2000. Early endosomal maturation of MHC class II molecules independently of cysteine proteases and $\mathrm{H}$ 2DM. EMBO J 19: 882-891.

Villadangos JA, Cardoso M, Steptoe RJ, van Berkel D, Pooley J, Carbone FR, Shortman K. 2001. MHC class II expression is regulated in dendritic cells independently of invariant chain degradation. Immunity 14: 739-749.

Villadangos JA, Schnorrer P, Wilson NS. 2005. Control of MHC class II antigen presentation in dendritic cells: A balance between creative and destructive forces. Immunol Rev 207: 191-205.

Viville S, Neefjes J, Lotteau V, Dierich A, Lemeur M, Ploegh H, Benoist C, Mathis D. 1993. Mice lacking the MHC class II-associated invariant chain. Cell 72: 635-648.

Vyas JM, Kim Y, Artavanis-Tsakonas K, Love JC, Van der Veen AG, Ploegh HL. 2007. Tubulation of class II MHC compartments is microtubule dependent and involves multiple endolysosomal membrane proteins in primary dendritic cells. J Immunol 178: 7199-7210.

Walseng E, Bakke O, Roche PA. 2008. Major histocompatibility complex class II-peptide complexes internalize using a clathrin- and dynamin-independent endocytosis pathway. J Biol Chem 283: 14717-14727.

Walseng E, Furuta K, Bosch B, Weih KA, Matsuki Y, Bakke O, Ishido S, Roche PA. 2010a. Ubiquitination regulates MHC class II-peptide complex retention and degradation in dendritic cells. Proc Natl Acad Sci 107: $20465-$ 20470.

Walseng E, Furuta K, Goldszmid RS, Weih KA, Sher A, Roche PA. 2010b. Dendritic cell activation prevents MHC class II ubiquitination and promotes MHC class II survival regardless of the activation stimulus. J Biol Chem 285: 41749-41754.

Wang K, Peterson PA, Karlsson L. 1997. Decreased endosomal delivery of major histocompatibility complex class II-invariant chain complexes in dynamin-deficient cells. J Biol Chem 272: 17055-17060.
Warmerdam PA, Long EO, Roche PA. 1996. Isoforms of the invariant chain regulate transport of MHC class II molecules to antigen processing compartments. J Cell Biol 133: $281-291$.

Watts C. 2012. The endosome-lysosome pathway and information generation in the immune system. Biochim Biophys Acta 1824: 14-21.

Weber DA, Evavold BD, Jensen PE. 1996. Enhanced dissociation of HLA-DR-bound peptides in the presence of HLA-DM. Science 274: 618-621.

West MA, Wallin RPA, Matthews SP, Svensson HG, Zaru R, Ljunggren H, Prescott AR, Watts C. 2004. Enhanced dendritic cell antigen capture via Toll-like receptor-induced actin remodeling. Science 305: 1153-1157.

Wilson JE, Katkere B, Drake JR. 2009. Francisella tularensis induces ubiquitin-dependent major histocompatibility complex class II degradation in activated macrophages. Infect Immun 77: 4953-4965.

Wubbolts R, Fernandez-Borja M, Oomen L, Verwoerd D, Janssen H, Calafat J, Tulp A, Dusseljee S, Neefjes J. 1996. Direct vesicular transport of MHC class II molecules from lysosomal structures to the cell surface. J Cell Biol 135: 611-622.

Wubbolts R, Fernandez-Borja M, Jordens I, Reits E, Dusseljee S, Echeverri C, Vallee RB, Neefjes J. 1999. Opposing motor activities of dynein and kinesin determine retention and transport of MHC class II-containing compartments. J Cell Sci 112: 785-795.

Yáñez-Mó M, Barreiro O, Gordon-Alonso M, Sala-Valdés M, Sánchez-Madrid F. 2009. Tetraspanin-enriched microdomains: A functional unit in cell plasma membranes. Trends Cell Biol 19: 434-446.

Yi W, Seth NP, Martillotti T, Wucherpfennig KW, Sant'Angelo DB, Denzin LK. 2010. Targeted regulation of selfpeptide presentation prevents type I diabetes in mice without disrupting general immunocompetence. J Clin Invest 120: 1324-1336.

Young LJ, Wilson NS, Schnorrer P, Proietto A, ten Broeke T, Matsuki Y, Mount AM, Belz GT, O’Keeffe M, Ohmura-Hoshino M, et al. 2008. Differential MHC class II synthesis and ubiquitination confers distinct antigen-presenting properties on conventional and plasmacytoid dendritic cells. Nat Immunol 9: 12441252

Zhong G, Romagnoli P, Germain RN. 1997. Related leucinebased cytoplasmic targeting signals in invariant chain and major histocompatibility complex class II molecules control endocytic presentation of distinct determinants in a single protein. J Exp Med 185: 429-438.

Zilber M, Setterblad N, Vasselon T, Doliger C, Charron D, Mooney N, Gelin C. 2005. MHC class II/CD38/CD9: A lipid-raft-dependent signaling complex in human monocytes. Blood 106: 3074-3081.

Zwart W, Griekspoor A, Kuijl C, Marsman M, van Rheenen J, Janssen H, Calafat J, van Ham M, Janssen L, van Lith M, et al. 2005. Spatial separation of HLA-DM/HLA-DR interactions within MIIC and phagosome-induced immune escape. Immunity 22: 221-233. 


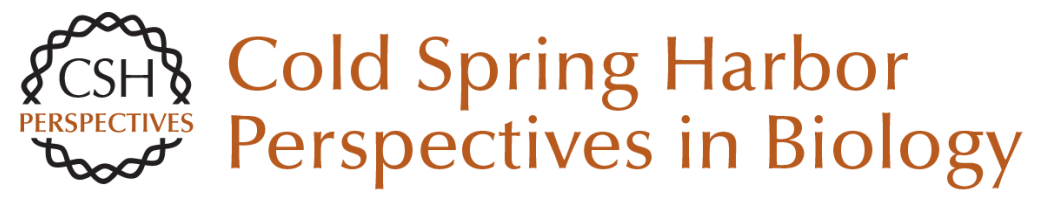

\section{MHC Class II Antigen Presentation by Dendritic Cells Regulated through Endosomal Sorting}

Toine ten Broeke, Richard Wubbolts and Willem Stoorvogel

Cold Spring Harb Perspect Biol 2013; doi: 10.1101/cshperspect.a016873

Subject Collection Endocytosis

Endocytosis: Past, Present, and Future Sandra L. Schmid, Alexander Sorkin and Marino Zerial

Rab Proteins and the Compartmentalization of the Endosomal System Angela Wandinger-Ness and Marino Zerial

Cargo Sorting in the Endocytic Pathway: A Key Regulator of Cell Polarity and Tissue Dynamics Suzanne Eaton and Fernando Martin-Belmonte

Unconventional Functions for Clathrin, ESCRTs, and Other Endocytic Regulators in the

Cytoskeleton, Cell Cycle, Nucleus, and Beyond:

Links to Human Disease

Frances M. Brodsky, R. Thomas Sosa, Joel A. Ybe, et al.

Endocytosis of Viruses and Bacteria Pascale Cossart and Ari Helenius

Lysosomal Adaptation: How the Lysosome Responds to External Cues Carmine Settembre and Andrea Ballabio

Reciprocal Regulation of Endocytosis and Metabolism Costin N. Antonescu, Timothy E. McGraw and Amira Klip

Endocytosis and Autophagy: Exploitation or Cooperation?

Sharon A. Tooze, Adi Abada and Zvulun Elazar
Imaging and Modeling the Dynamics of

Clathrin-Mediated Endocytosis

Marcel Mettlen and Gaudenz Danuser

Endocytic Accessory Factors and Regulation of

Clathrin-Mediated Endocytosis

Christien J. Merrifield and Marko Kaksonen

The Complex Ultrastructure of the Endolysosomal

System Judith Klumperman and Graça Raposo

The Biogenesis of Lysosomes and

Lysosome-Related Organelles

J. Paul Luzio, Yvonne Hackmann, Nele M.G.

Dieckmann, et al.

Endocytosis, Signaling, and Beyond Pier Paolo Di Fiore and Mark von Zastrow

Clathrin-Independent Pathways of Endocytosis Satyajit Mayor, Robert G. Parton and Julie G. Donaldson

The Role of Endocytosis during Morphogenetic Signaling Marcos Gonzalez-Gaitan and Frank Jülicher

Role of Endosomes and Lysosomes in Human Disease Frederick R. Maxfield

For additional articles in this collection, see http://cshperspectives.cshlp.org/cgi/collection/

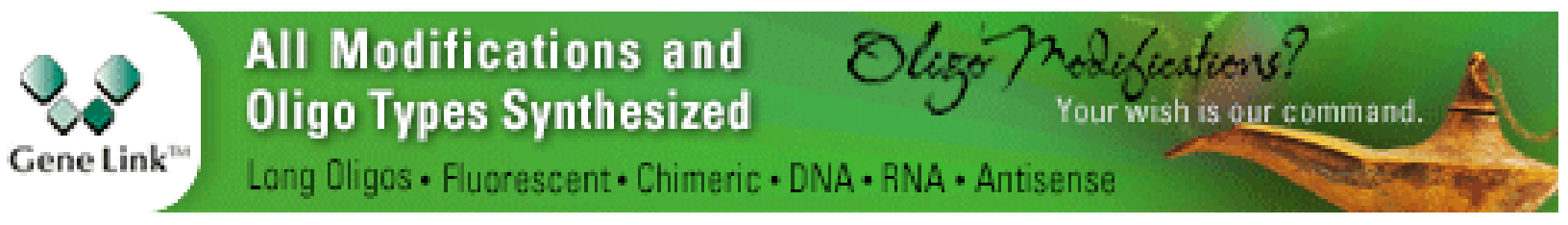


For additional articles in this collection, see http://cshperspectives.cshlp.org/cgi/collection/

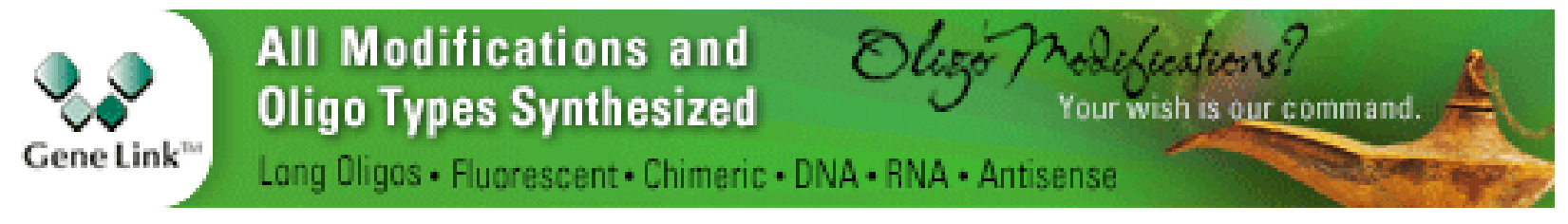

Copyright @ 2013 Cold Spring Harbor Laboratory Press; all rights reserved 